\title{
Topography of Visual Cortex Connections with Frontal Eye Field in Macaque: Convergence and Segregation of Processing Streams
}

\author{
Jeffrey D. Schall,' Anne Morel,' Dana J. King, ${ }^{1}$ and Jean Bullier ${ }^{3}$ \\ 'Department of Psychology, Vanderbilt University, Nashville, Tennessee 37240, '2Laboratory for Functional \\ Neurosurgery, University Hospital, $\mathrm{CH}-8091$ Zurich, Switzerland, and ${ }^{3}$ Cerveau et Vision, INSERM 371,69500 Bron, \\ France
}

The primate visual system consists of at least two processing streams, one passing ventrally into temporal cortex that is responsible for object vision, and the other running dorsally into parietal cortex that is responsible for spatial vision. How information from these two streams is combined for perception and action is not understood. Visually guided eye movements require information about both feature identity and location, so we investigated the topographic organization of visual cortex connections with frontal eye field (FEF), the final stage of cortical processing for saccadic eye movements. Multiple anatomical tracers were placed either in parietal and temporal cortex or in different parts of FEF in individual macaque monkeys. Convergence from the dorsal and ventral processing streams occurred in lateral FEF but not in medial FEF. Certain extrastriate areas with retinotopic visual field organizations projected topographically onto FEF. The dorsal bank of the superior temporal sulcus projected to medial FEF; the ventral bank, to lateral FEF, and the fundus, throughout FEF. Thus, lateral FEF, which is responsible for generating short saccades, receives visual afferents from the foveal representation in retinotopically organized areas, from areas that represent central vision in inferotemporal cortex and from other areas having no retinotopic order. In contrast, medial FEF, which is responsible for generating longer saccades, is innervated by the peripheral representation of retinotopically organized areas, from areas that emphasize peripheral vision or are multimodal and from other areas that have no retinotopic order or are auditory.

[Key words: frontal eye field, saccade, eye movement, visual system, extrastriate cortex, oculomotor system, visual cortex, parallel pathways, frontal cortex]

Visual processing in the cerebral cortex proceeds through multiple visual areas into a dorsal pathway responsible for spatial vision and into a ventral pathway responsible for object vision

\footnotetext{
Received July 29. 1994; revised Jan. 19, 1995; accepted Jan. 23, 1995.

We thank Sandrine Beaumont. Noelle Boyer, Judy Ives, Laura Trice, and Renee Wall for skilled technical assistance, Sarah Aderholt. Sarah Laborde, Frank Tu, and Christy Whalley for assistance with data acquisition and analysis, and the reviewers for helpful comments. J. Schall was supported by R01EYox890, a fellowship from the Altred P. Sloan Foundation, a grant from the McDonnell-Pew Program in Cognitive Neuroscience, P30-EY08126 to the Vanderbilt Vision Research (enter, and P30-HD15052 to the John F. Kennedy Center for Research on Education and Hunan Develomatent. A. Monel was supported by the Fondation pour la Recherche Médicale and by R01-EY02686 10 J. Kalas.

Correspondence should be addressed to Dr. Jeffrey D. Schall. Department of Psychology. Wilson Hall, Vanderbilt University, Nashville, TN 37240.

Copyright (s) 1995 Sociely for Neuroscience (0270-6474/95/154464-24\$05.00/0
}

(Ungerleider and Mishkin, 1982; Morel and Bullier, 1990; Baizer et al., 1991; Young, 1992). How information from the various cortical areas is combined to generate perception and action is not known. The investigation of visually guided eye movements may be a domain in which this issue can be examined effectively because information about both object identity and spatial location must be combined to produce accurate eye movements. During natural viewing, saccades of less than $10^{\circ}$ amplitude. which are by far the most common (Bahill et al., 1975), direct gaze to conspicuous and informative features in the scene (reviewed by Viviani, 1990; Rayner, 1992). Thus, both object vision and spatial vision are needed for these saccades. Larger amplitude saccades, however, being guided less by object recognition processes because of reduced peripheral visual acuity, are involved in orienting responses to peripheral visual as well as to acoustic stimuli and therefore are more closely related to spatial vision. This study examined the pattern of connections of frontal eye field (FEF) and surrounding prefrontal cortex with extrastriate visual areas and other postcentral cortical areas because FEF represents a final stage of cortical processing for visually guided, purposive saccades (Bruce and Goldberg, 1985 Segraves and Goldberg, 1987; Schall, 1991b; Dassonville et al., 1992; Segraves, 1992).

A number of studies have investigated FEF connectivity (reviewed by Leichnetz and Goldberg, 1988). This study departs from previous work in several ways. First, two or three tracers were injected simultaneously in the same animal. The tracers were placed either within functionally distinct areas-posterior parietal and inferior temporal cortex-or within different zones of one functionally identified area-the frontal eye field. This method makes it possible for the first time to cxamine directly the convergence and segregation of visual processing streams in frontal cortex. Second, the description of architectonic and functional areas in prearcuate cortex (Bruce et al., 1985; Stanton et al., 1989; Preuss and Goldman-Rakic, 1991) and in extrastriate visual cortex has become more refined (reviewed by Colby and Duhamel, 1991; Felleman and Van Essen, 1991). The locations of tracer injections and the spatial distribution of labeled terminals and neurons were analyzed in relation to these improved architcetonic descriptions. Finally, prearcuatc cortcx has a rough retinotopic organization of saccade amplitude and visual field eccentricity. Shorter saccades are generated by lateral FEF, and longer saccades, by medial FEF (Robinson and Fuchs, 1969; Bruce et al., 1985). Also, the receptive fields of visual cells in lateral prearcuate cortex represent the central visual field, and dorsomedial cells, the peripheral visual field (Suzuki and Azu- 
ma, 1983). There is little information about the topography of visual afferents to FEF. For example, it is not known whether retinotopically organized visual areas such as MT project topographically onto FEF. Nor is it known whether areas that have an overrepresentation of the central or of the peripheral visual field project differentially onto medial or lateral FEF. The results of this investigation provide information that is necessary for interpreting the functional properties of neurons in FEF in relation to saccades guided by different kinds of visual information.

Preliminary reports of these data have appeared (Morel and Bullier, 1987; Schall et al., 1991, 1993a).

\section{Materials and Methods}

Three Macaca mulatta and four Macaca fascicularis monkeys, weighing 2-8 kg. provided the data for this study. All animals were cared for in accordance with the National Institutes of Health Guide for the Care and Use of Laboratory Animals. Data from the four cynomolgus monkeys were collected at Vision et Motricité, INSERM 94, where multiple tracer injections were made into posterior parielal and inferior temporal cortex; we have already described the organization of connectivity among prestriate visual areas (Morel and Bullier, 1990). Data from the three rhesus monkeys in which multiple tracer injections were made into FEF were collected at Vanderbilt University; we have already described the organization of connectivity with supplementary eye field in these cases (Schall et al., 1993b).

Tracer injections into parietal and temporal cortex. The methods used for this portion of the study are detailed by Morel and Bullier (1990). Animals were premedicated with chlorpromazine $(0.5 \mathrm{mg} / \mathrm{kg}$, i.m.) and dexamethasone $(1 \mathrm{mg} / \mathrm{kg}$, i.m. $)$. Anesthesia was induced with ketamine $(20 \mathrm{mg} / \mathrm{kg}, \mathrm{i} . \mathrm{m}$.) and maintained during surgery by periodic intravenous injections of a mixture of alfadolone acetate and alfaxolone (alfatesin). Injections were made along multiple tangential and subpial penetrations in the inferior temporal gyrus and in pentrations oriented $30-40^{\circ}$ from the parasagittal plane in the lateral bank of the intraparietal sulcus. Labeled amino acids consisted of an equal part mixture of tritiated proline (CEA, $1-\left[4,5-{ }^{\prime} \mathrm{H}\right]$, specific activity $\left.32 \mathrm{Ci} / \mathrm{mmol}\right)$ and tritiated leucine (CEA, $1-\left[2,4,5-{ }^{-} \mathrm{H}\right]$, specific activity $150 \mathrm{Ci} / \mathrm{mmol}$ ) that were evaporated and reconstituted in saline to a final concentration of $80 \mu \mathrm{Ci} / \mu \mathrm{l}$. The WGA-HRP was injected as equal part volumes of $10 \%$ WGA-HRP and free, unconjugated HRP in saline. The FB and DY were used as described helow.

Tracer injections into FEF. Placement of tracer injections in the prearcuate gyrus was guided by the results of intracortical microstimulation and surface landmarks under aseptic conditions in ketamine anesthetized monkeys. Animals were premedicated with atropine $(0.05$ $\mathrm{mg} / \mathrm{kg}$ ) and dexamethasone $(1 \mathrm{mg} / \mathrm{kg})$. Anesthesia was induced with ketanine $(30 \mathrm{mg} / \mathrm{kg})$ and maintained with periodic injections $(15 \mathrm{mg} /$ $\mathrm{kg}$ ). Throughout the procedure animals were maintained on a heating pad; their temperature, respiration, and heart rate were monitored and maintained within optimal limits. A large craniotomy was filled with silicone fluid. A stainless steel bar was cemented to the skull to restrain the head without the stereotaxic instrument. A photograph of the exposed cortex was taken, and a magnified print was made to record and guide stimulation and injection penetrations. Penetrations were made under visual guidance via a surgical microscope. Constant-current stimulation trains lasting $50-500 \mathrm{msec}$ were used; each train consisted of symmetric biphasic square wave pulses of $0.4 \mathrm{msec}$ total duration in $500 \mu \mathrm{m}$ steps to explore the prearcuate gyrus. If the initial exploratory current evoked an eye movement, the current level at which an eye movement could be evoked on $50 \%$ of the stimulus trains was taken as the threshold current. Eye movements evoked by intracortical microstimulation were monitored visually and agreed upon by two observers. Following recovery from anesthesia, analgesics (butorphanol, $0.05 \mathrm{mg} /$ $\mathrm{kg}$, or banamine, $1 \mathrm{mg} / \mathrm{kg}$ ) were given as needed.

The tracers were prepared and injected according to procedures described in Morel and Bullier (1990) and Schall et al. (1993b). Monkeys AM13 and AM55 received injections of the fluorescent dyes fast blue (FB), diamidino yellow (DY), and fluorogold (FG). Disappointingly, few neurons were labeled with FG, but they will be described. In monkey AM25, paired injections of wheat germ-agglutinated horseradish peroxidase (WGA-HRP) and nuclear yellow (NY) were placed. Fluo- rescent dyes were injected in 3\% aqueous solution. WGA-HRP was injected in $2 \%$ saline. The injections were made with a $I$ or $5 \mu l \mathrm{Ham}-$ ilton syringe onto which a pulled micropipette was attached. Injections were placed at a rate of $0.1 \mu \mathrm{l} / 20 \mathrm{~min} / \mathrm{mm}$ along $4-6 \mathrm{~mm}$ long penetrations into the rostral bank of the arcuate sulcus.

Histological processing. Conventional histological procedures were used (Huerta et al., 1987; Morel and Bullier, 1990; Schall et al., 1993b). Animals that received only fluorescent dyes recovered for a period of 10-15 d, and animals that received WGA-HRP + NY or WGA-HRP + tritiated amino acids survived $3 \mathrm{~d}$. In one case (AM8), fluorescent dyes were injected $10 \mathrm{~d}$ before the injection of WGA-HRP. After perfusion, the brains were removed, photographed, and separated into two blocks by a coronal section rostral to the central sulcus. Only the hemisphere ipsilateral to the injections was studied. The rostral blocks were sectioned coronally in all cases except AM55 in which parasagittal sections were used. The caudal blocks were sectioned coronally except for AM4, which was cut instead horizontally. Sections were 40 or $50 \mu \mathrm{m}$ thick, and those containing fluorescent material were immediately mounted, coverslipped, and stored at $4^{\circ} \mathrm{C}$. An alternate series of sections were stained for Nissl (cresyl violet or thionin) or myelin (Gallyas, 1979). In cases with WGA-HRP injections (e.g., AM8 and AM25), a series of sections was processed for HRP histochemistry with the low artifact tetramethyl benzidine (TMB) method (Gibson et al.. 1984). In AM2, a series was processed for autoradiography; sections were mounted and dipped in Ilford emulsion, exposed at $4{ }^{\circ} \mathrm{C}$ for $16-24$ weeks, and developed in Kodak PI.12, fixed, and counterstained with cresyl violet.

Sections containing fluorescent labeling were observed under ultraviolet illumination ( $355-425 \mathrm{~nm})$. FB-labeled neurons exhibited a blue cytoplasm. FG-labeled neurons exhibited a characteristic golden filling of the soma and proximal dendrites. DY- and NY-labeled neurons exhibited a yellow nucleus. WGA-HRP labeling was observed under bright- and dark-field illumination. Contours of the sections and the distribution of labeled neurons were digitized using a computer morphometry system via $x-y$ position encoders coupled to the microscope stage. Nissl- or myelin-stained sections were then projected onto the drawings to trace contours of cortical layers, limits of sulci, and the positions of cyto- and/or myeloarchitectonic borders.

Identification of cortical areas. Cortical areas were identified by myelo- and cytoarchitectural criteria, described below. Borders and transitions were identified independently by two investigators.

The boundaries for areas V2 and the V 3 complex were guided by previously published maps (Burkhalter et al., 1986; Newsome et al., 1986; Van Essen et al., 1986; Gattass et al., 1988). The border between area V2 and the dorsal part of area V3 (V3d) in the depth of the lunate sulcus was recognized in Nissl-stained sections by a transition from small to relatively large, heavily stained pyramidal cells in layer 3 . This cytoarchitectonic border corresponded to a transition from lighter myelin staining in area $\mathrm{V} 2$ to the presence of more pronounced radial fibers in area V3d and the absence of an inner band of Baillarger. The borders in the inferior occipital sulcus between area $V 2$ and the ventral part of area $V 3$ (V3v), and that between areas V2 and V4 near the junction between the lunate sulcus and the inferior occipital sulcus were more difficult to assign. Based on myeloarchitecture (Van Essen et al.. 1986) and by comparison with previously published maps (Van Essen and Zeki, 1978; Gattass et al., 1988) we identified area V3A adjacent to $\mathrm{V} 3 \mathrm{~d}$ on the annectant gyrus and rostral bank of the lunate sulcus. Bordering V3A dorsally, area V4 occupied the lip of the lunate sulcus and prelunate gyrus and was characterized by lighter myelin staining than in $V 3$ or $V 3 A$, making the bands of Baillarger appear distinct. In the superior temporal sulcus, $\mathrm{V} 4$ borders area $\mathrm{V} 4 \mathrm{t}$, which is distinguished by more pale and diffuse myelin staining (Maguire and Baizer. 1984: Ungerleider and Desimone, 1986a). Ventrally, the anterior border of V4 is unclear, so our assignment was guided by physiological mapping studies (Maguire and Baizer, 1984; Gattas et al., 1988). The dorsal prelunate gyrus was assigned to area DP, which has been distinguished from V4 in terms of retinotopic organization and cortical connections (Maguire and Baizer, 1984; Gattass et al., 1988: Andersen et al., 1990a).

Our analysis of the architecture of the caudal superior temporal sulcus conformed to earlier descriptions. On the caudal lower bank of the superior temporal sulcus area MT was defined by its dense myelin staining (Van Essen et al., 1981; Desimone and Ungerleider, 1986). The dorsal bank of the superior temporal sulcus is occupied by area MST, a myeloarchitectonically heterogeneous region (Desimone and Ungerleider, 1986; Ungerleider and Desimone, 1986b; Komatsu and Wurtz, 1988; Boussaoud et al., 1990). The portion of MST on the dorsal bank 
of the superior temporal sulcus is distinguished by a densely myelinated zone. Area FST in the fundus of the superior temporal sulcus was identified by its thick radial fascicles (Ungerleider and Desimone, 1986a). The rostral superior temporal sulcus was analyzed according to the description of Seltzer and Pandya (1978) and of Baylis et al. (1987) emphasizing transitions observed in Nissl-stained sections. Although many of the transitions were subtle, we were able to reliably identify areas TAa and TPO on the dorsal bank, areas PGa and IPa at the fundus, and areas TEa and TEm on the lower bank. On the inferior temporal gyrus area, TEO exlended fiom the inferior occipital sulcus to the rostral end of the posterior middle temporal sulcus, according to a recent map (Boussaoud et al., 1991). Rostral to TEO were areas TEm and TE3 (Seltzer and Pandya, 1978). Area PITd on the floor of the superior temporal sulcus rostral to MT and medial to TEO was distinguished according to its recent description (Boussaoud et al., 1991; Distler et al., 1993)

The lateral bank of the intraparietal sulcus has been partitioned according to a number of schemes over the years. We have identified the myeloarchitectonic boundaries described by others (e.g., Ungerleider and Desimone, 1986b: Andersen et al., 1990a; Blatt et al., 1990) and have attempted to use a nomenclature consistent with recent findings of the functional and anatomical organization of the intraparietal sulcus. Area 7a (corresponding to area PGc or PP) on the convexity of the gyrus was characterized by radial fascicles of fibers. Adjacent to the convexity, on the lateral bank a more lightly myelinated strip was referred to as LIPd. A densely myelinated zone extended from the ventral border of LIPd to a point dorsal to the fundus; this zone was identified as LIPv. The ventral boundary of LIPv was often difficult to discern in our material. Recent recordings throughout the depth of the lateral bank of the intraparietal sulcus have demonstrated that the transition in myelin staining corresponds to a physiological transition from dorsal cells rclated to saccades to ventral neurons exhibiting visual direction spec ificity and activity during pursuit eye movements (Colby et al., 1993) The ventral area is VIP, first identified by its connections with MT (Maunsell and Van Essen, 1983; Ungerleider and Desimone, 1986b) Caudally, the myeloarchitecture was somewhat different; the identification of LIPd was less certain even though a densely myelinated ventral zone continuous with LIPv was evident. Nevertheless, in some cases we were not confident assigning any borders at these caudal levels (Colby et al., 1988: Matelli et al., 1991).

Our analysis of the cytoarchitecture and myeloarchitecture of frontal cortex was guided by established descriptions (Walker, 1940; von Bonin and Bailey, 1947), supplemented by newer findings (Stanton et al., 1989: Preuss and Goldman-Rakic, 1991). The rostral bank and convexity of the arcuate sulcus is a heterogeneous area that can be subdivided into at least four areas. The photomicrographs in Figure 1 illustrate some of the variation in cytoarchitecture and myeloarchitecture in the arcuate sulcus. The region in the rostral bank of the arcuate sulcus containing concentrated large pyramidal cells in layer $V$ has been identified as corresponding to the functionally defined FEF (Stanton et al., 1989). The ventrolateral portion of this zone has been further distinguished by the presence of large pyramidal cells in layer 3 as well as layer 5 (Walker, 1940). The ventrolateral zone is areat 45 , and the dorsomedial zone is area 8A. Further parcellation is possible based on cytoand myeloarchitectonic differences (Preuss and Goldman-Rakic, 1991). The portion of area 45 extending to the fundus has a more loosely organized granular layer with a less clear border between layers 4 and 5 than the cortex that lies near the lip which has a better defined layer 4. The deeper zone is denoted area $45 \mathrm{~b}$, and the more superficial zone, area 45 a. All of area 45 is myelin dense with poor differentiation between the bands of Baillarger and thick vertical and horizontal fascicles. Area 45b has slightly lighter myelin staining in the supragranular layers

Area $8 \mathrm{~A}$ can be subdivided also. The cortex within the medial portion of the rostral bank of the arcuate sulcus contains few if any large pyramidal cells in layer 3 and a loosely organized granular layer and is referred to as area $8 \mathrm{Ac}$. The transitional zone that forms the rostral boundary of area $8 \mathrm{Ac}$ and area $45 \mathrm{a}$ and adjoins the caudal boundary of area 46 is referred to as area $8 \mathrm{Ar}$. In Nissl, area $8 \mathrm{Ar}$ has few large pyramidal cells and a more clearly defined layer 4 as compared to $8 \mathrm{Ac}$. In myelin. area $8 \mathrm{Ar}$ is characterized by conspicuous bands of Baillarger and radial libers. The area we designate as $8 \mathrm{Ac}$ comesponds to areas $8 \mathrm{Ac}$ and $8 \mathrm{Am}$ of Preuss and Goldman-Rakic (1991) because in our material we could not distinguish these two areas.

The following evidence indicates that $\mathrm{FEF}$ corresponds to areas $8 \mathrm{Ac}$, $45 \mathrm{a}$, and $45 \mathrm{~b}$, and probably not to 8 Ar. First, saccades are elicited by intracortical microstimulation with lower thresholds from sites on the rostral bank of the arcuate sulcus, in the region corresponding to areas 8Ac, 45a, and 45b; higher thresholds are found at sites on the rostral convexity, in the region corresponding to $8 \mathrm{Ar}$ (Bruce et al., 1985: Stanton et al., 1989). Second, the large pyramidal cells in layer 5 that project to the superior colliculus and brainstem (e.g., Fries. 1984) are not as dense in $8 \mathrm{Ar}$ as they are in $8 \mathrm{Ac}, 45 \mathrm{a}$, and $45 \mathrm{~b}$. An earlier study correlated the presence of this cytoarchitectural feature with location of the functionally defined FEF (Stanton et al., 1989). Finally, in cases AM13 and AM55, presented below, microstimulation at the sites of the tracer injections made in 45a and $8 \mathrm{Ac}$ elicited saccadic eye movements. The ventral and dorsal boundaries of FEF are less clear.

Two-dimensional reconstructions of the cortex. Flattened representations of the cortex were constructed to analyze the spatial distribution of the injection sites, labeled cells and terminals and architectural borders. Overall, the approach was based on the method of Van Essen and Maunsell (1980); however, different procedures were used for different cortical regions. The two-dimensional reconstructions of the parietal and temporal injection sites (Fig. 4) and the other flattened representations of frontal cortex (Figs. 2, 5-7) were constructed according to the procedures detailed by Morel and Bullier (1990) and Perkel et al. (1986). The reconstructions of the FEF injection sites (Fig. 8) and unfolded superior temporal sulcus (Figs. 14-16) were done by shaping wire to conform to the contour of layer IV in scctions scparated by $500 \mu \mathrm{m}$. The points of highest curvature of sulci and fundi, areal boundaries, and injection boundaries were marked on the wire. The wires were spaced according to the scale and gradually straightened, preserving neighborhood relationships. Because of its lower curvature, two-dimensional representations of the lateral bank of the intraparietal sulcus (Figs. 11-13) were constructed by computer. Using graphics software. the following sequential procedure was done on a digitized representation of the contour of layer 4, labeled neurons, and areal boundaries. Each layer 4 line segment, along with the neurons and areal boundaries located directly above or below, was rotated to a standard orientation. Successive line segments and the associated cells were placed contiguous with neighboring segments. This procedure was carried out for each serial section; then the straightened representations were positioned the appropriatc distance apart to form a final two-dimensional representation.

\section{Results}

\section{Prearcuate cortex connections with posterior parietal and} inferior temporal cortex

Paired injections of different tracers were placed in posterior parictal and inferior temporal cortex of four monkeys. One of the key findings of this investigation is illustrated by each of these four cases-whereas area LIP is connected with a large part of the prearcuate cortex, areas TEO and caudal TE are connected to a restricted ventrolateral region including areas $45 \mathrm{a}$, $45 \mathrm{~b}$, and 12 . Thus, the zone in lateral FEF responsible for generating shorter saccades receives convergent afferents from the two functional branches of the extrastriate visual pathway. In contrast, the zone of medial FEF responsible for generating larger saccades is interconnected with the parietal but not temporal lobe.

In case AM2, distinct anterograde tracers were injected into the lateral bank of the intraparietal sulcus and into the surface of the inferior temporal gyrus at the boundary between areas TEO and caudal TE. Figure 2 shows the distribution of the terminal label in a flattened reconstruction of the cortex surrounding the arcuate and principal sulci. Terminal labeling from the parietal cortex injection was much more extensive than that issued by the temporal cortex injection. The LIP injection yielded terminal label in areas $8 \mathrm{Ac}, 45 \mathrm{a}$, and $45 \mathrm{~b}$ in the rostral bank of the arcuate sulcus in addition to label in area $8 \mathrm{Ar}$ on the prearcuate convexity, in area 12 ventral to the principal sulcus, and in a caudal, ventral portion of area 46 in the principal sulcus. Label from the LIP injection was also found in area 6 , in the dorsal caudal bank of the arcuate sulcus. Terminal label from 

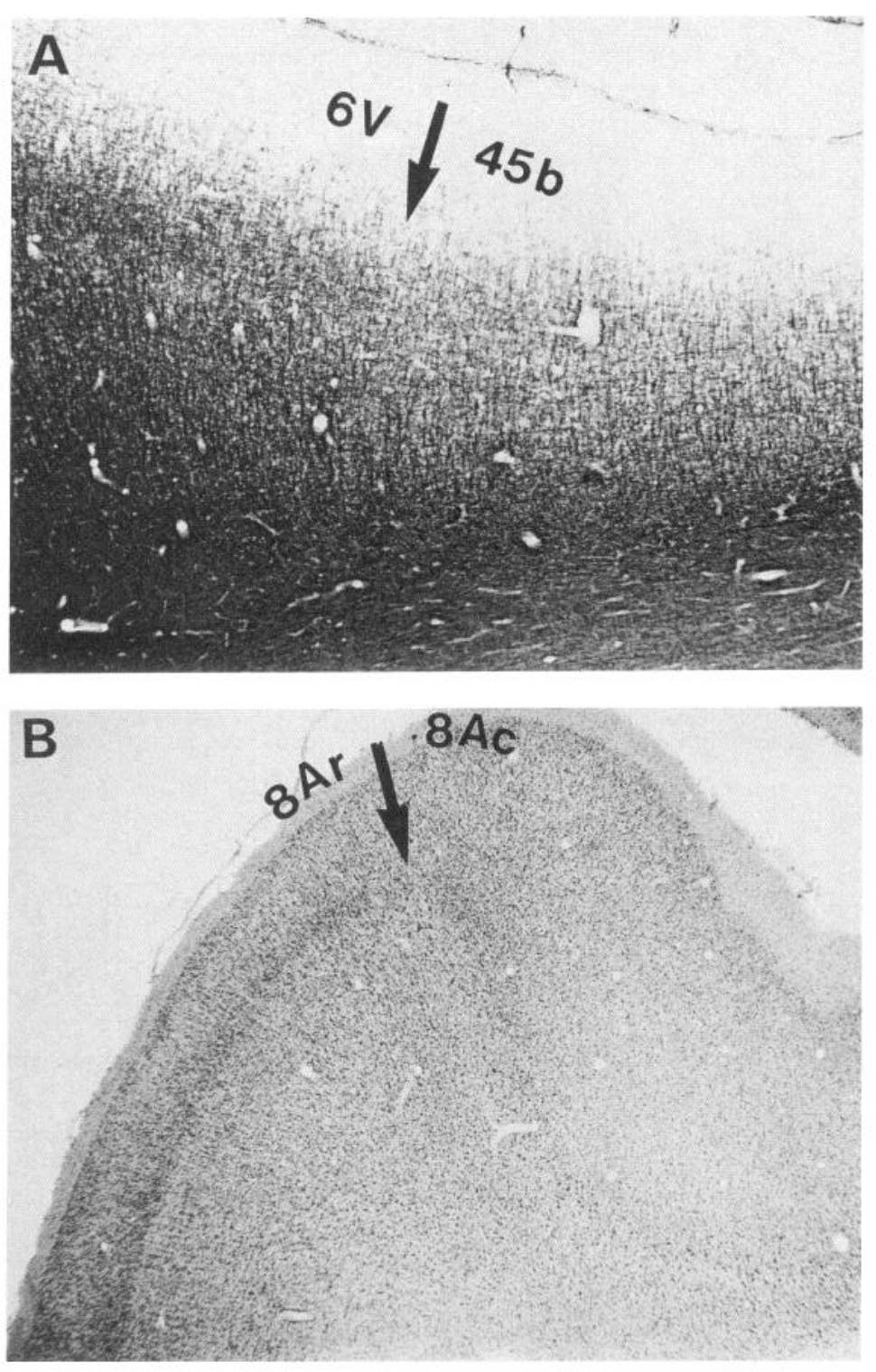

$1 \mathrm{~mm}$

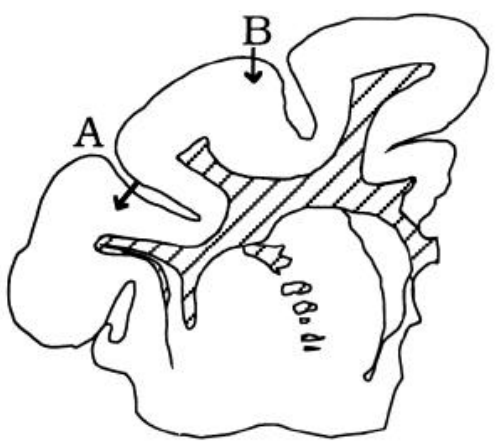

AM4 Sections

2529

Figure 1. Representative sections showing the variation in myeloarchitecture $(A)$ and cytoarchitecture $(B)$ that defined some of the borders of the areas identified in prearcuate cortex. The coronal section shows the locations where the photomicrographs were taken.

the injection in TEO and caudal TE was much more limited. A band of terminal label was observed in area 45a that continued into area 12. The band of label overlapped almost completely with the label from the LIP injection. Isolated zones of innervation from TEO and caudal TE were also observed in ventral area 46 in the principal sulcus.

Photomicrographs from a zone of overlap of orthograde label from the parietal and temporal cortex injections in the inferior limb of the arcuate sulcus are shown in Figure 3. The label from a restricted injection in LIP was broadly distributed but concentrated in two clusters: one near the fundus and another at the lip of the sulcus. The terminal label occupied layer 4 but extended into supra- and infragranular layers near the lip and into the infragranular layers near the fundus. The label from TEO was found throughout the bank but with two concentrated zones. The terminal label was located in layer 4 but also in the supragran- ular layers. The terminal label from the temporal lobe injection overlapped that from the parietal lobe injection fully near the fundus and partially near the lip of the sulcus. Thus, axons from both posterior parietal and inferior temporal cortex terminate within the same local zones of prearcuate cortex.

The pattern of feedback projections from frontal cortex to posterior parietal and inferior temporal cortex was investigated in three cases. The locations of the injections in parietal and temporal cortex are shown in Figure 4 in flattened two-dimensional reconstructions. Figures showing the location of the injections in brain sections are in Morel and Bullier (1990). In case AM1, one tracer was injected into the lateral bank of the intraparietal sulcus occupying most of LIPd and the dorsal half of $\mathrm{LIPv}$, and a relatively large injection of a different tracer was made on the surface of the inferior temporal gyrus, including rostral TEO and caudal TEm and TE3. In case AM4, the parietal 


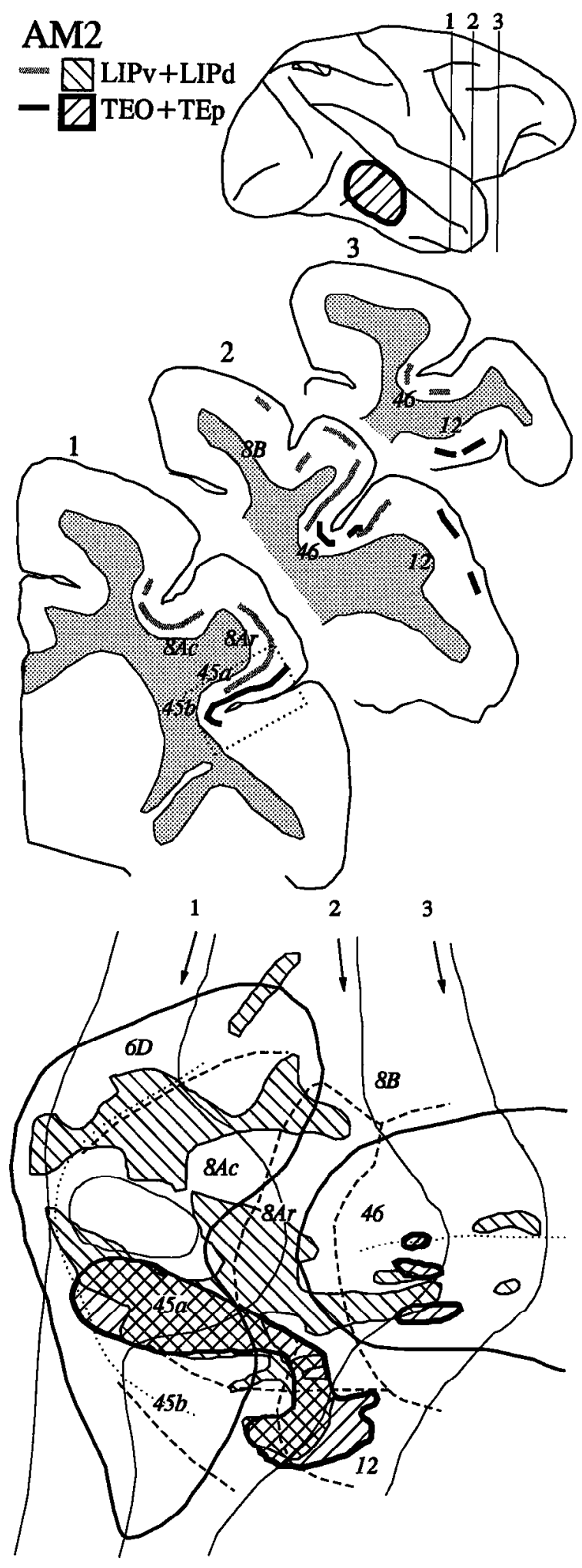

Figure 2. Distribution of anterograde label in arcuate cortex following paired injections of tritiated amino acids (AA) in area LIP of posterior parietal cortex and of WGA-HRP in rostral TEO and caudal area TE in the inferior temporal gyrus in case AM2. The locations of the injections are indicated on a dorsolateral view of the brain. Representative coronal sections are shown from the levels indicated on the lateral view of the cortex. The overall spatial distribution of the terminal labeling is shown in the two-dimensional reconstruction. Dashed lines indicate architectonic boundaries. Regions of dense label from the injection in LIP are indicated by the solid gray line in the coronal sections and by the injection occupied much of LIPd, dorsal LIPv, and invaded $7 \mathrm{a}$; the temporal injection was confined to TEO on the convexity of the inferior temporal gyrus. In case AM8, three tracer injections were made; one filled rostral LIPd and dorsal LIPv, another was made into area $7 \mathrm{a}$ on the convexity of the inferior parietal lobule, and a smaller injection of a the third tracer, was placed in posterior TE.

The distribution of retrogradely labeled neurons in prearcuate frontal cortex observed in case AM1 is illustrated in a twodimensional reconstruction in Figure 5. The injection in inferior temporal cortex was relatively large, corresponding in size and location to the orthograde tracer injection in case AM2. Accordingly, the general pattern of distribution of the retrogradely labeled neurons in frontal cortex was very similar to the pattern of terminal label observed in that case. A high density of neurons labeled by the injection of DY in area LIP were found in areas $8 \mathrm{Ac}, 45 \mathrm{a}$, and $45 \mathrm{~b}$ in the rostral bank of the arcuatc sulcus. As observed in the previous anterograde label case, the distribution of parietal lobe connections appears to be interrupted in the arcuate sulcus caudal to the principal sulcus. A somewhat lower density of cells labeled by the parietal injection was found in area $8 \mathrm{Ar}$ on the prearcuate convexity. A large number of neurons labeled by the LIP injection were found on both banks of caudal principal sulcus in area 46. A limited number of neurons labeled from the LIP injection were found in area 12, ventral to the principal sulcus, in area 6 in the caudal bank of the dorsal limb of the arcuate sulcus, and in area $8 \mathrm{~B}$ at the tip of the dorsal limb of the arcuate sulcus. In the representative individual sections shown in the second part of Figure 5, neurons labeled by the LIP injection of DY are also seen in orbitofrontal cortex, on the dorsomedial convexity in the supplementary eye field, and in area 24 of the cingulate gyrus. The serial sections also demonstrate that labeled neurons were observed in supraand infragranular layers.

In case AM1, fewer neurons were labeled in prearcuate cortex by the injection in TEO and caudal TE as compared to the number and spatial extent of neurons labeled by the tracer injection in LIP. The labeled neurons were found in upper and lower cortical layers in a limited region in areas $45 \mathrm{a}$ and $45 \mathrm{~b}$ in the rostral bank of the inferior limb of the arcuate sulcus. Clusters of neurons labeled by the temporal lobe injection were also found in ventral area $8 \mathrm{Ar}$, ventral area 46 in the principal sulcus, and in area 12. Also of note, no labeled neurons were observed in SEF, and very few were in area 24 . In spite of the large degree of overlap in the spatial distribution of neurons labeled by the injections in the two cortical regions, we observed few doublelabeled neurons $(<7 \%)$.

In case AM4, one tracer was injected in the lateral bank of the intraparietal sulcus and another in the inferior temporal gyrus (Fig. 4). The distribution of neurons labeled by the injection in LIPd and dorsal LIPv was generally the same as that observed in the previous case (Fig. 6). Ventrolaterally, there were two foci of label, the larger concentrated in area $45 \mathrm{~b}$, and the smaller, in

$\leftarrow$

left hatched regions in the two-dimensional reconstructions. Zones of orthograde WGA-HRP label are indicated by the black in the coronal sections and by the right hatched regions with thicker borders in the flattened representation. The fundus of sulci is indicated by a thin dotted line, and the lip, by a thicker line. The dotted rectangle superimposed on section 1 indicates the region shown in the photomicrographs in Figure 3. 

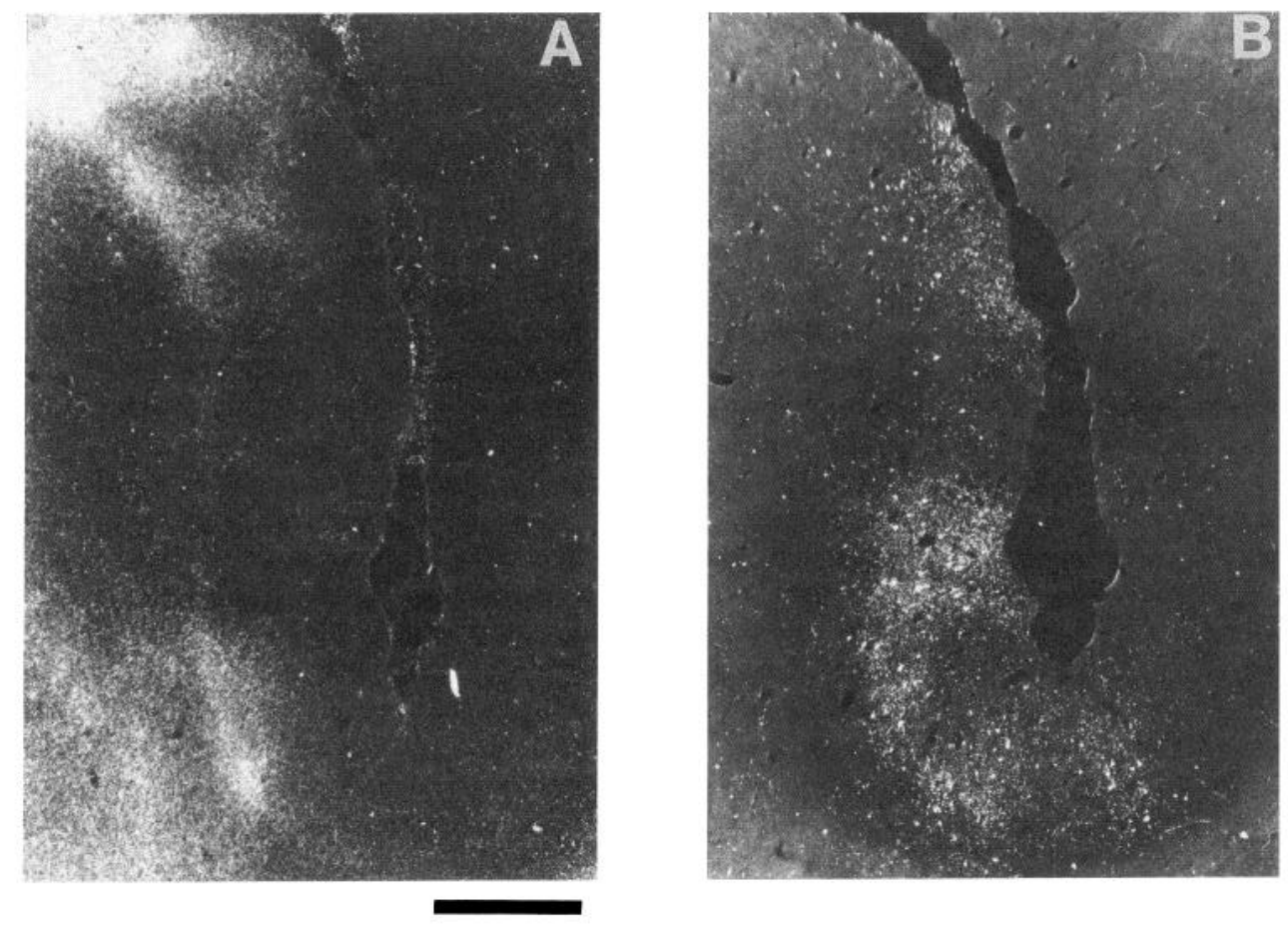

Figure 3. Photomicrographs of adjacent sections showing label in rostral bank of arcuate sulcus posterior parietal and inferior temporal cortex. A, Terminal label from a tritiated amino acid injection in LIP. $B$, Terminal label and retrogradely labeled neurons from a WGA-HRP injection in TEO/TE. The location of region shown in the micrograph is indicated by the rectangle in Figure 2. The sections show the medial-rostral bank of the inferior limb of the arcuate sulcus (area 45a). Medial is left; dorsal is up. Scale bar, $1 \mathrm{~mm}$. area 45a. Dorsomedially, there was a large area of label extending from postarcuate area $6 \mathrm{D}$ through areas $8 \mathrm{Ac}$ and $8 \mathrm{Ar}$, branching into area $8 \mathrm{~B}$ and into area 46 in the principal sulcus. In the individual sections, neurons labeled by the parietal injection are also evident in the orbital sulcus, in cingulate cortex and in the SEF.

In contrast to case AM1, the inferior temporal lobe injection in AM4 was smaller and restricted to dorsal area TEO. In this monkey, neurons were labeled in a restricted ventrolateral focus in area 45a and a small zone in lateral 8Ac. The neurons in area $8 \mathrm{Ac}$ labeled by the TEO injection partially overlapped regions of neurons labeled from the LIP injection. The ventrolateral neurons labeled from TEO covered more of area $45 \mathrm{a}$ than did the neurons labeled from LIP. Neurons from the injection in TEO were not found in area 12 ventrally nor in the SEF dorsally. Neurons labeled by both injections were found in upper and lower cortical layers. The pattern of label from injections restricted to area TEO was similar in another monkey (not shown).

The lateral bank of the intraparietal sulcus is functionally and anatomically distinguishable from the convexity of the inferior parietal lobule (e.g., Andersen et al., 1990a,b). To provide more information about the relative connectivity of these regions in comparison to inferior temporal cortex with frontal cortex, three tracers were used in case AM8 (Fig. 4). One was injected into LIPd and dorsal LIPv; another was injected into the convexity of the inferior parietal lobule in area 7a. A third tracer was injected into the inferior temporal gyrus (Fig. 7). The distribution of neurons labeled by the LIP injection in prearcuate cortex in this case was generally similar to that observed in the other cases except that no interruption was observed in the dispersion of neurons within the rostral bank of the arcuate sulcus. We speculate that this more complete labeling may be attributed to the fact that the tracer injection extended further toward the fundus of the intraparietal sulcus in this case, thus involving more of LIPv (see below). Neurons labeled by the LIP injection were found over a broad region extending from postarcuate area 6 into area $8 \mathrm{Ac}$ medially and areas $45 \mathrm{~b}$ and $45 \mathrm{a}$ laterally. A band of labeled cells passed through area $8 \mathrm{Ar}$ into caudal area 46 in and ventral to the principal sulcus. An island of labeled neurons was also observed in area 8B. In the coronal sections, neurons labeled from LIP are also found in orbitofrontal cortex, in cingulate cortex area 24 , and in SEF as well as in the rostrally adjacent area 9 .

Neurons labeled from the injection in area $7 \mathrm{a}$ were dispersed around the arcuate and principal sulci and were found in upper and lower cortical layers. Two clusters of neurons were observed in the caudal bank and convexity of the arcuate sulcus in area 6 ; these groups of neurons only partially overlapped the neurons labeled by the injection into area LIP. A small cluster of cells labeled from $7 \mathrm{a}$ was observed in area $45 \mathrm{~b}$ and another in area $45 \mathrm{a}$; these neurons were in the same region as the neurons labeled from LIP. Another group of neurons labeled by the 7a injection was found at the limit of the upper limb of the arcuate sulcus, in dorsomedial area $8 \mathrm{Ar}$; this group of neurons partially overlapped that distribution of neurons labeled from LIP. A band of labeled neurons was found in the ventral bank of the principal sulcus, at the ventrolateral limit of the neurons in area 46 labeled by LIP injection. A small collection of labeled neurons was also observed in area 12. In the coronal sections, a few neurons labeled from $7 \mathrm{a}$ may also be seen in both the dorsal and ventral banks of the cingulate sulcus and on the mesial surface as well as in orbitofrontal cortex.

The tracer injection in inferior temporal cortex in this case differed from that in the previous cases by being smaller and located further rostral in dorsal area TE. A dense collection of neurons labeled by this injection was observed in areas 45a and $45 \mathrm{~b}$ that almost entirely overlapped with cells labeled by the injection into LIP. In contrast to the previous case, cells labeled by the temporal lobe injection were also found further rostral in areas 46 and 12. One group of labeled neurons in caudal area 12 overlapped the zone labeled by the injection in area 7a. Another large cluster of neurons labeled from TE was located in caudal area 46 , ventral to the tip of the principal sulcus; this group was intermingled with neurons labeled from the LIP in- 

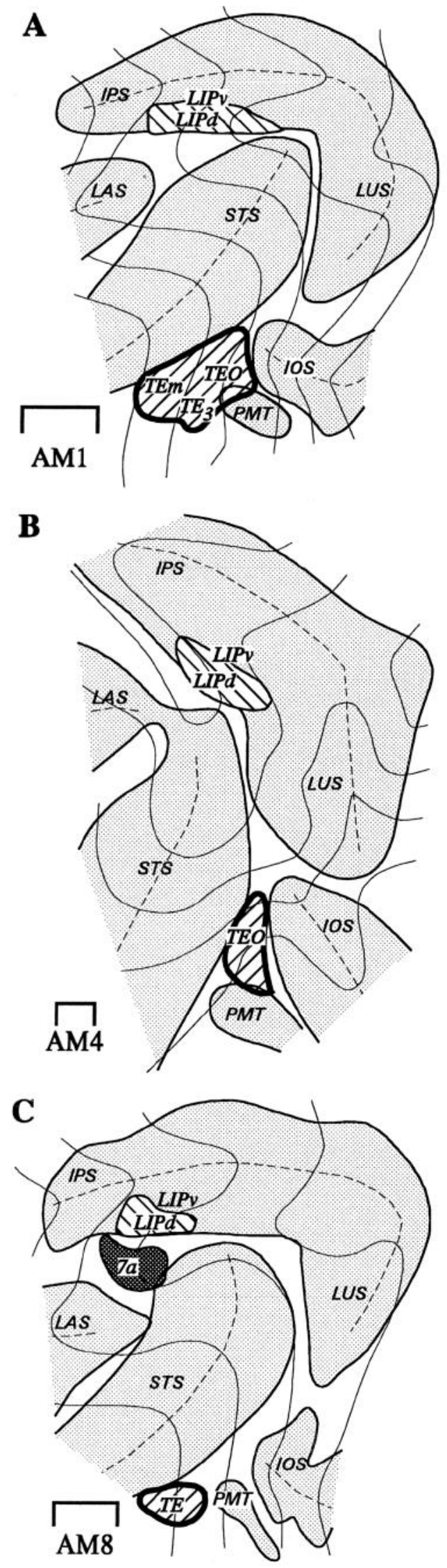

Figure 4. Sites of retrograde tracer injections in posterior parietal and inferior temporal cortex. Two-dimensional reconstructions of posterior jection. Two other small islands of neurons connected with temporal lobes were found in ventral area 46 in the principal sulcus; these groups overlapped largely but not entirely the neurons labeled from LIP. In the coronal sections, neurons labeled from temporal lobe were seen in orbital cortex but not in SEF or area 24.

To summarize the connectivity of arcuate cortex with posterior parietal and inferior temporal cortex, area LIP is interconnected with a large part of prearcuate cortex extending from the caudal bank of the arcuate sulcus into the caudal portion of the principal sulcus. Area TEO is connected with a limited part of the rostral bank of the ventrolateral arcuate sulcus. Caudal area TE is also connected with the rostral bank of the ventrolateral arcuate sulcus but is also connected with parts of caudal area 12 and 46. Tracer injections placed further rostral in area TE did not label neurons in area 45, but did label cells in areas 12 and 46 (data not illustrated from the left hemisphere of case AM2 and from case AM9, Morel and Bullier, 1990). Finally, area 7a is more diffusely connected with the cortex surrounding the arcuate sulcus. To explore the pattern of connectivity of prearcuate cortex in more detail, injections of multiple tracers were placed in the rostral bank of the arcuate sulcus in three additional monkeys.

\section{Locations of injections in prearcuate cortex}

The three cases in which tracers were injected into the rostral bank of the arcuate sulcus differed in the location of the injections relative to one another and to the cytoarchitectural areas. Figure $8 A$ shows a summary map of the results of microstimulation that guided the injection placement in case AM13. Eye movements were elicited by stimulation with less than $50 \mu \mathrm{A}$ from a range of sites in the rostral bank of arcuate sulcus. Although the monkey was anesthetized with ketamine, a gradual change in evoked saccade amplitude was observed as penetrations shifted along the sulcus. Along the inferior limb the eye movements became too small to detect. Increasing the stimulus train duration allowed improved detection of these short saccades somewhat. We are probably underestimating the ventrolateral limit of the excitable zone because we were unable to reliably detect very short saccades $\left(<5^{\circ}\right)$ and because the monkey was anesthetized with ketamine, which is known to disrupt the brainstem neural integrator (Bruce and Russo, 1987; Godaux et al., 1990). For this reason, one tracer was injected just lateral to the penetration in which evoked saccades could be detected. Figure $8 B$ illustrates the location and size of the tracer injections in case AM13 in a flattened reconstruction of prearcuate cortex. The ventrolateral injection (right hatch) spanned the boundary between area $45 \mathrm{a}$ in the rostral bank and area $8 \mathrm{Ar}$ on the convexity of the gyrus but did not reach the fundus. Dorsomedially, longer saccades were evoked. At some sites these long saccades were accompanied by pinna movements. At sites further rostral

$\leftarrow$

cortex are shown. Shaded regions indicate buried portions of the labeled sulci. The thin lines indicate the contours of layer 4. A, Injections in case AM1. The DY injection in the lateral bank of the intraparietal sulcus is indicated by left hatching. The FB injection in inferior temporal cortex is indicated by right hatching. B, DY (left hatching) and FB (right hatching) injections in case AM4. C, DY (left hatching), FB (dark shading), and WGA-HRP (right hatching) injections in case AM8. IOS, inferior occipital sulcus; IPS, intraparietal sulcus; $L A S$, lateral sulcus; $L U S$, lunate sulcus; $P M T$, posterior middle temporal sulcus; $S T S$, superior temporal sulcus. Scale bars, $5 \mathrm{~mm}$. 

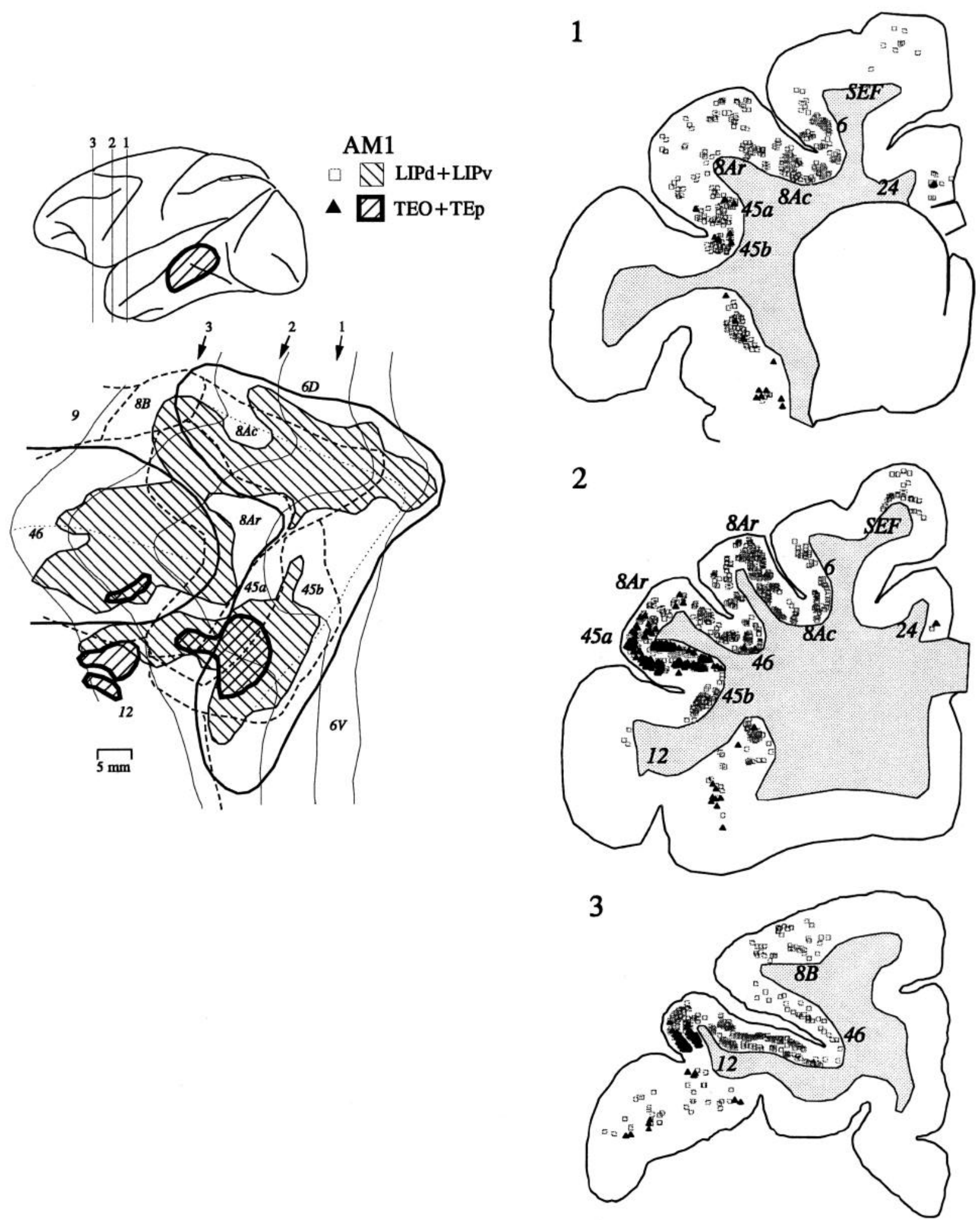

Figure 5. Retrograde label in arcuate cortex following DY injection into LIP and FB injection into TEO and caudal TE in case AMI. The location of the injections is indicated on the lateral view of the brain. Representative coronal sections are shown from the levels indicated on the lateral view of the brain. The distribution of retrogradely labeled neurons from the two injections is shown in representative coronal sections and in a flattened reconstruction of the arcuate sulcus and caudal end of the principal sulcus. Neurons labeled by DY injected in LIP are indicated by open gray squares in the coronal sections and by left hatched regions in the flattened reconstruction. Neurons labeled by the FB injection in TEO and caudal TE are represented by solid black triangles in the sections and by right hatched regions in the two-dimensional view. Architectural areas are labeled. $S E F$, supplementary eye field. 


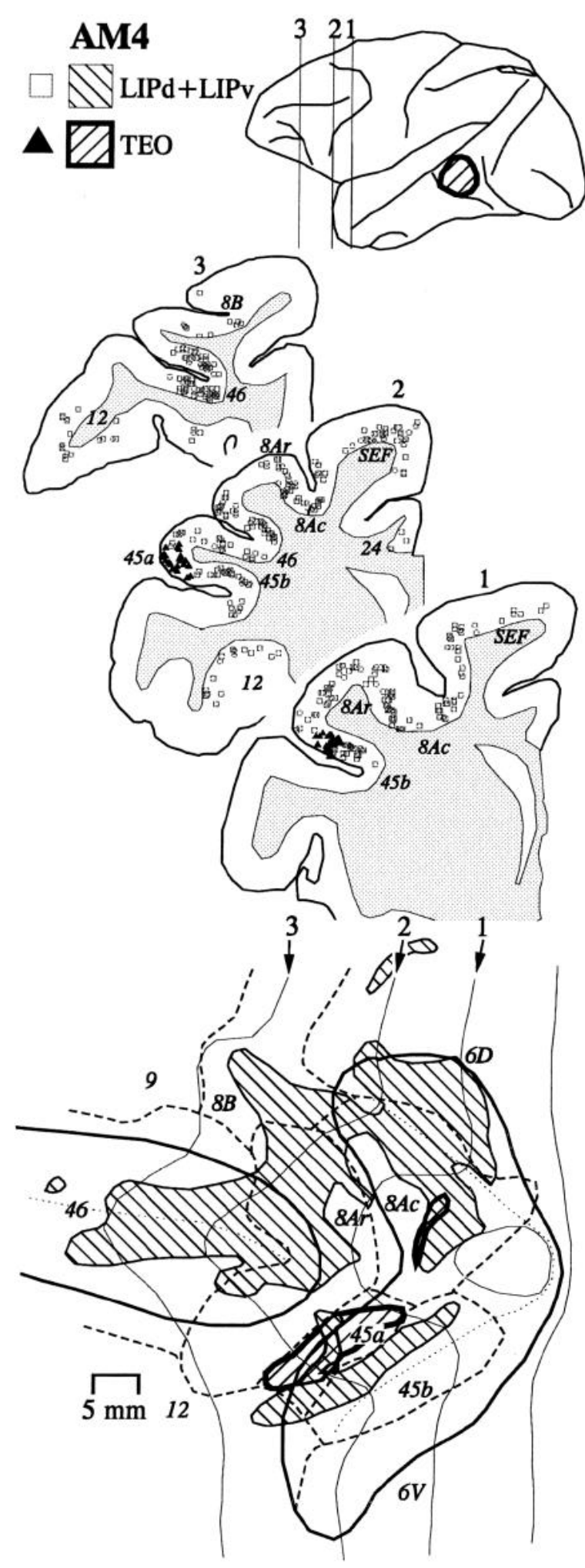

Ftgure 6. Retrograde label following DY injection into LIP and FB injection into TEO in case AM4. Conventions are as in Figure 5.

along the upper limb of the arcuate sulcus only pinna movements were elicited. Another tracer was injected at the boundary of the zone from which the pinna movements were elicited. This injection (dark shading) was located mainly in area $8 \mathrm{Ac}$ in the rostral bank but extended into area $8 \mathrm{Ar}$ on the medial convexity of the arcuate sulcus. A third tracer was injected in the center of the region from which intermediate amplitude saccades were evoked. This injection (left hatching) was adjacent to the FB injection; it was located primarily in the lateral edge of area $8 \mathrm{Ac}$ but also extended slightly into area 45 laterally and area $8 \mathrm{Ar}$ rostrally. Unfortunately, both the ventrolateral and the central injections penetrated the superficial layers of the postarcuate gyrus.

The injections in case AM25 were guided by the surface landmarks of the arcuate sulcus. The resulting injections involved a large part of the rostral bank of the arcuate sulcus in this monkey (Fig. $8 C$ ). The ventrolateral injection (right hatching) was restricted to areas $45 \mathrm{a}$ and $45 \mathrm{~b}$ in the rostral bank and extended into area $8 \mathrm{Ar}$ on the convexity. The dorsomedial injection (left hatching) was in area $8 \mathrm{Ac}$ and included some of medial $8 \mathrm{Ar}$. Microstimulation results in case AM55 were not as clear as those in AM13, but eye movements were evoked within a limited part of the anterior bank of the arcuate sulcus with low intensity stimulation. The two-dimensional reconstruction of frontal cortex for this case is shown in Figure $8 D$. The ventrolateral injection (right hatching) was centered on the lip of the sulcus in area 45a. In interpreting the data, it is important to note that this injection was the most laterally placed in area 45 of all three cases, but this injection also penetrated the superficial layers of the postarcuate gyrus. The dorsomedial injection (left hatching) extended to the fundus in area $8 \mathrm{Ac}$ and included the caudal convexity in $8 \mathrm{Ar}$.

\section{Overview of prearcuate afferents}

Figures 9 and 10 illustrate coronal sections showing the pattern of retrogradely labeled cells observed following tracer injections into medial and lateral prearcuate cortex in cases AM13 and AM55. Neurons were labeled in many prestriate visual areas by injections in medial and lateral FEF, but various patterns of topographic or differential labeling were observed. Rare labeled cells were observed in V2 and V3, and a somewhat higher density was observed in V4. The highest density of neurons were labeled in the intraparietal sulcus, mesial cortex including the cingulate gyrus, the superior temporal sulcus and the inferior temporal gyrus. The pattern of label will be described for each of these regions in more detail.

\section{Lateral intraparietal area}

Consistent with the findings described for the first four monkeys, in every case we studied, LIP projected to both medial and lateral portions of prearcuate cortex, including areas $8 \mathrm{Ar}$ and $8 \mathrm{Ac}$ medially and areas $45 \mathrm{a}$ and $45 \mathrm{~b}$ laterally. Neurons labeled by FEF injections were observed in supra- and infragranular layers in LIP of every case. Even in sections with high concentrations of neurons labeled by medial and lateral FEF injections fewer than $10 \%$ of the cells were double labeled. Figure 11 illustrates the distribution of retrogradely labeled neurons in the lateral bank of the intraparietal sulcus resulting from paired prearcuate injections in case AM13. Neurons labeled from the ventrolateral and central FEF injections were found throughout the rostrocaudal extent of the architectonically defined LIP area, extending from the approximate midpoint of the intraparietal sulcus caudal to the level of the annectant gyrus. Sparse neurons from both injections were found on the rostral convexity, in area 7a. An equally low density of neurons was found in LIPd. By far, the 

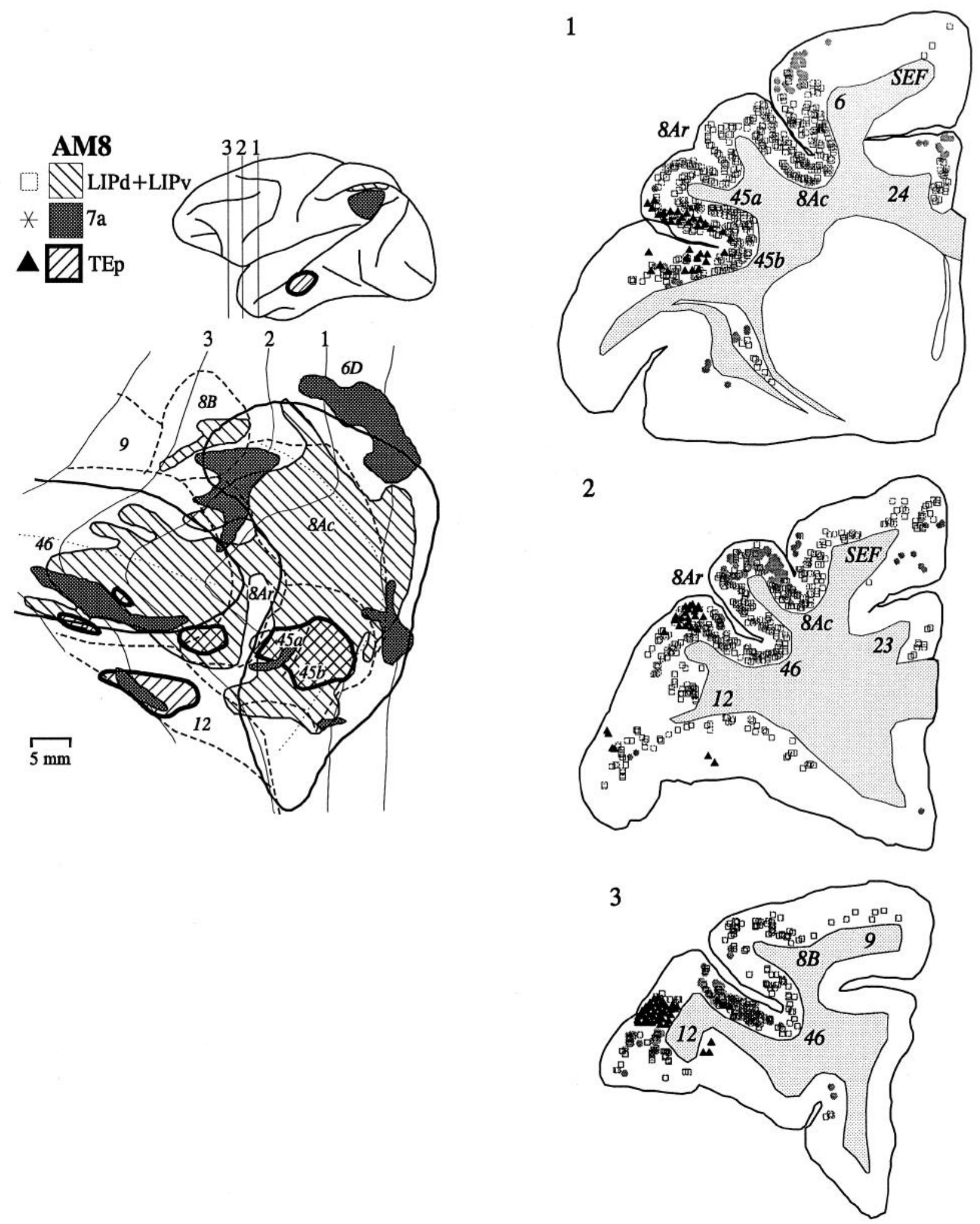

Figure 7. Retrograde label following combined DY injection into LIP, HRP injection into caudal TE, and FB injection into 7a in case AM8. Conventions are as in Figure 5 with the addition of representing neurons labeled by an FB injection in area 7a with solid gray circles in coronal sections and darkly shaded regions in the flattened reconstruction.

highest density of retrogradely labeled cells was in LIPv. Few labeled neurons were observed in VIP.

Neurons labeled by the lateral and the more medial FEF injections were extensively intermingled in dorsal LIPv. Interdi- gitated bands were found in rostral and ventral LIPv, and scattered clusters were seen in LIPd and caudal LIPv. Further caudal, at the level of the annectant gyrus, many neurons labeled from the ventrolateral injection and scattered neurons labeled 

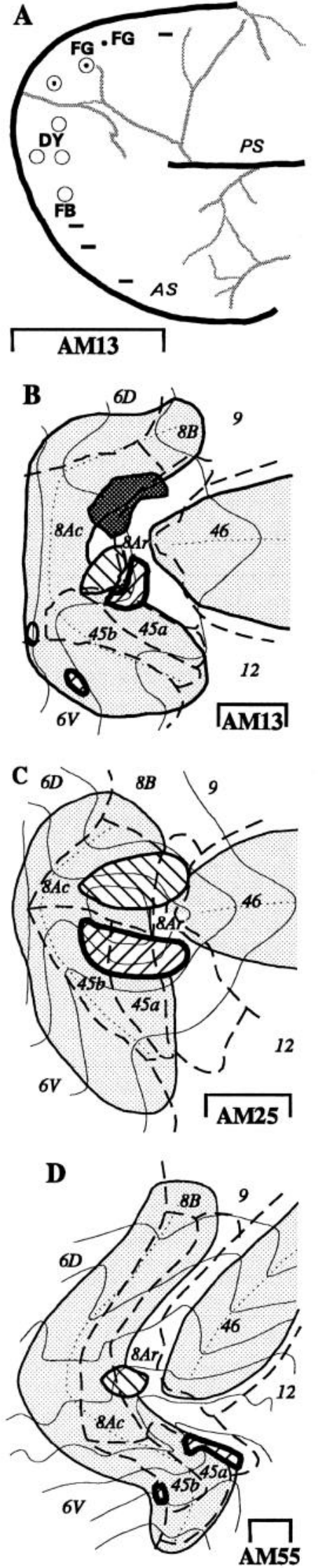

Figure 8. Prearcuate injection sites. A, Map of electrical stimulation results in case AM13. The locations of the arcuate (AS) and principal from the central FEF injection were found deeper in the sulcus. The large degree of overlap in the spatial distribution of the labeled cells may be attributable to the neighboring location of the injections in FEF (Fig. 8). No neurons were labeled in the intraparietal sulcus by the dorsomedial FG injection that was placed in the upper limb of the arcuate sulcus; we are not sure if this is due to the vicissitudes of the tracer or signifies a real finding because FG-labeled neurons were observed in the superior temporal gyrus (see Figs. 9, 14).

Figure 12 shows the results of paired injections in case AM55, in which the prearcuate injections were further separated than in case AM13. Labeled cells were found from the level of the annectant gyrus caudally extending rostrally approximately three-fourths the length of the intraparietal sulcus, once again dispersed throughout the architectonically defined LIP. A few cells labeled by the injection involving area $8 \mathrm{~A}$ were found in rostral area $7 \mathrm{a}$. In comparison to case AM13, there were more cells labeled in LIPd, wherein neurons labeled by the lateral prearcuate injection were more common rostrally and cells labeled by the centromedial prearcuate injection were more common caudally. The highest density of neurons labeled by both prearcuate injections was in LIPv. Compared to AM13, the spatial distribution of the labeled neurons exhibited somewhat less overlap. As in LIPd, in dorsal LIPv the cells labeled by the lateral area $45 \mathrm{a}$ injection were located rostral to cells labeled by the central area $8 \mathrm{Ac}$ injection. The few neurons found in VIP were labeled mostly by the more medial prearcuate injection.

The distribution of retrogradely labeled cells from prearcuate injections in case AM25 is shown in Figure 13. The rostrocaudal extent of the labeled neurons covered almost four-fifths the length of the intraparietal sulcus. Label from both injections extended from the lip to the fundus. Unlike the previous two cases, for some reason the labeled neurons were found more frequently in the supragranular layers. In general, the injection involving areas $45 \mathrm{a}$ and $45 \mathrm{~b}$ labeled cells that were located rostral to those labeled by the injection into area $8 \mathrm{Ac}$. The rostral cells labeled by the lateral prearcuate injection were restricted primarily to LIPv. The caudal cells labeled by the medial prearcuate injection were more concentrated in LIPd but spread into 7a and LIPv; they did not distribute much in area VIP. Thus, in this case, the neurons labeled by medial and lateral prearcuate injections were generally more segregated than what was observed in the other two cases.

\section{Mesial cortex}

Neurons were consistently labeled on the mesial cortical surface in the parietooccipital (PO) visual area, in the medial dorsal

$\leftarrow$

(PS) sulci are shown. Conjugate eye movements were evoked from sites indicated by open circles. Pinna movements were elicited by microstimulation of sites marked by closed circles, and combined eye and pinna movements, from sites marked by open circles with center dot. No movements were detected from sites indicated by solid line. The location of the FB, DY, and FG injections is also indicated on the map. $B$, Flattened reconstruction of the injection sites in case AM13. Shaded regions represent buried portions of sulci. The contours of layer 4 at $1500 \mu \mathrm{m}$ intervals are shown. Dashed lines signify areal boundaries. Dotted lines indicate the fundus. The most heavily shaded area marks the FG injection; the left hatching indicates the DY, and the right hatching, the FB injection. $C$, Reconstruction of injections in case AM25. Left hatching indicates the NY injection site, and right hatching, the WGA-HRP injection. D, Reconstruction of injections in case AM55. Left hatching shows the DY injection, and right hatching, the FB. Rostral, right; medial, upward. Scale bars, $5 \mathrm{~mm}$. 


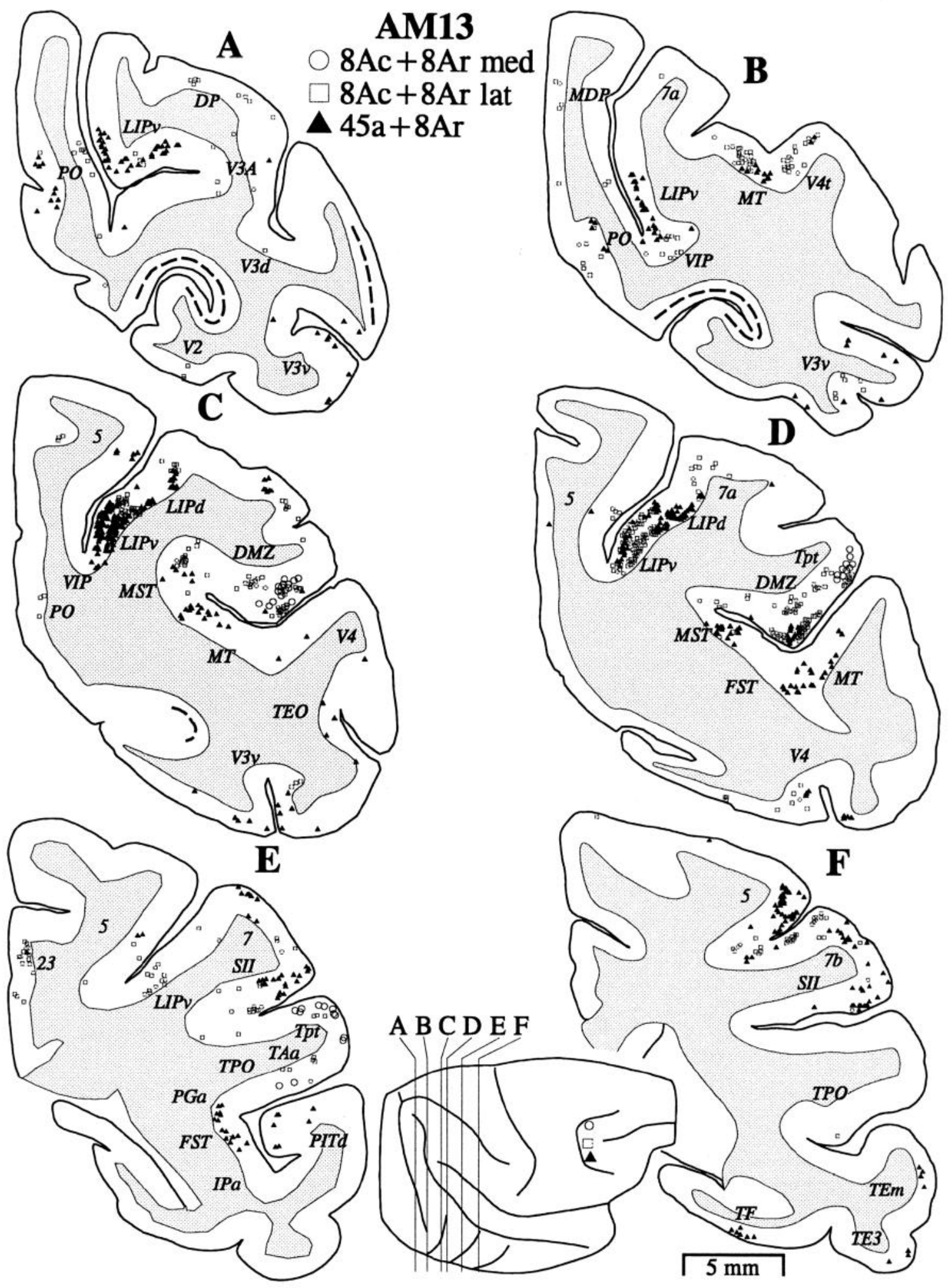

Figure 9. Representative coronal sections from the levels indicated on the lateral brain view for case AM13. Solid black triangles indicate the position of neurons labeled by the FB injection in area 45a; open gray squares show the position of neurons labeled by the DY injection in lateral $8 \mathrm{Ac}$, and large open circles show the location of neurons labeled by the FG injection in medial 8Ac. The dashed line indicates V1, and other cortical areas are labeled as follows: 5 , cortical area $5 ; 7 a$, area $7 \mathrm{a} ; 7 b$, area $7 \mathrm{~b} ; 23$, area $23 ; D M Z$, densely myelinated zone of medial superior temporal visual area; $D P$, dorsal prelunate area; $F S T$, fundus of superior temporal sulcus visual area; $I P a$, area IPa; $L I P d$, dorsal lateral intraparietal area; $L I P v$, ventral lateral intraparietal area; $M D P$, medial dorsal parietal area; $M S T$, medial superior temporal visual area; $M T$, middle temporal visual area; $P G a$, area $\mathrm{PGa} ; P I T d$, dorsal posterior inferior temporal area; $P O$, parietooccipital visual area; $S 2$, second somatosensory area; TAa, area TAa; TE3, area TE3; TEm, area TEm; TEO, area TEO; $T F$, area TF; $T P O$, area TPO; $T p t$, area Tpt; $V 2$, visual area $2 ; V 3 a$, visual area V3A; $V 3 d$, dorsal visual area $3 ; V 3 v$, ventral visual area $3 ; V 4$, visual area $4 ; V 4 t$, transitional area $V 4 I$; $V I P$, ventral intraparietal area. 




Figure 10. Representative coronal sections for case AM55. Conventions are as in Figure 9.

parietal (MDP) area, and in area 23 in the cingulate gyrus. The pattern of label for case AM13 is shown in Figures 9 and 11. In caudal cortex (Fig. 9A), cells in PO were labeled from both the injection in areas $8 \mathrm{Ac}$ and $8 \mathrm{Ar}$ and from the injection in dorsomedial area 45a plus 8Ar. The labeled neurons were most commonly in the infragranular layers. The two populations of labeled neurons were segregated on the mesial wall and on the medial bank of the intraparietal sulcus; this segregation corresponds to the representation of the upper and lower visual field in PO (Colby et al., 1988). Further rostral (Figs. 9B; 11, section 2 ), neurons labeled by the DY injection in 8Ac were found dorsally in the infragranular layers on the medial wall of parietal 


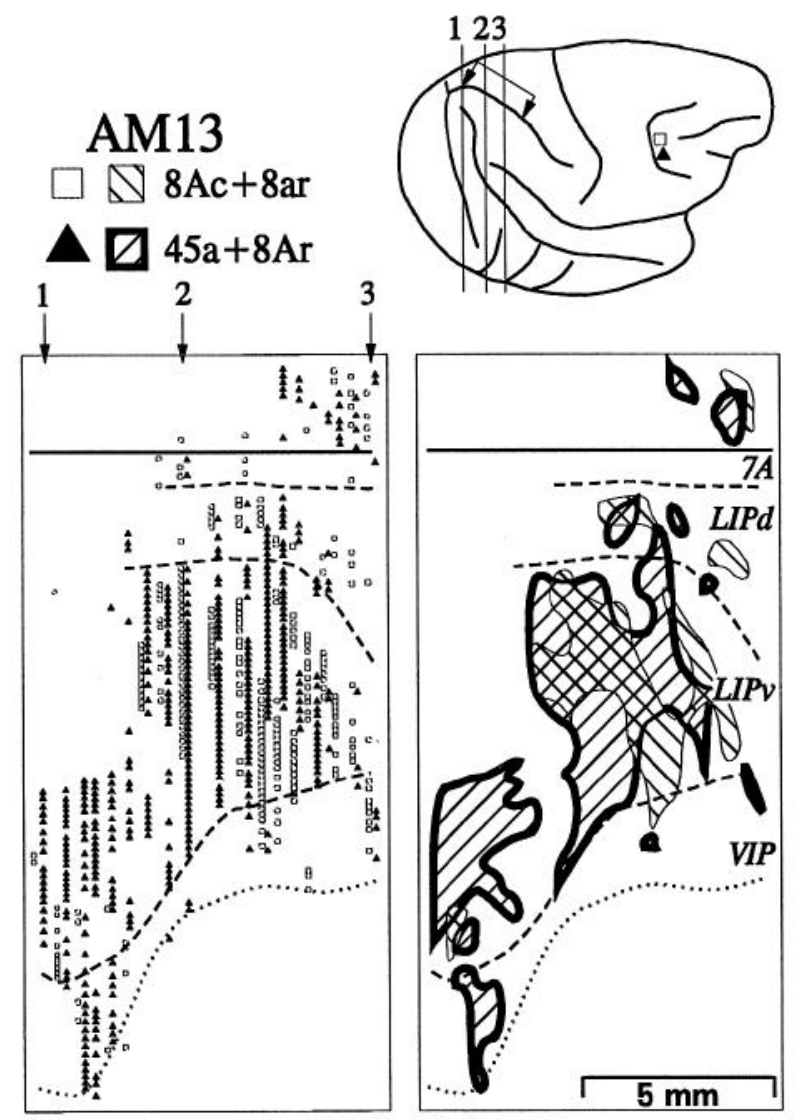

1

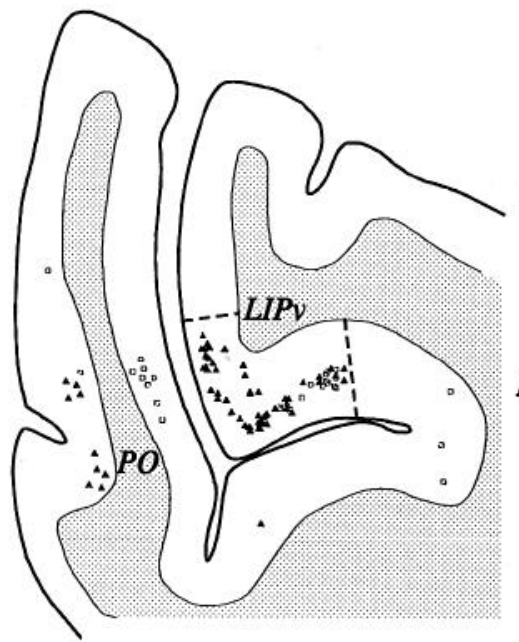

2

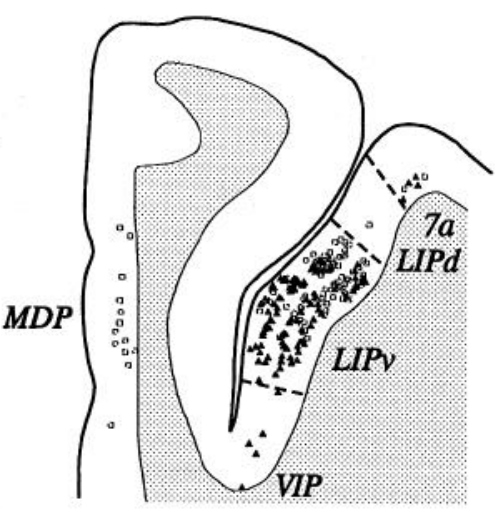

3

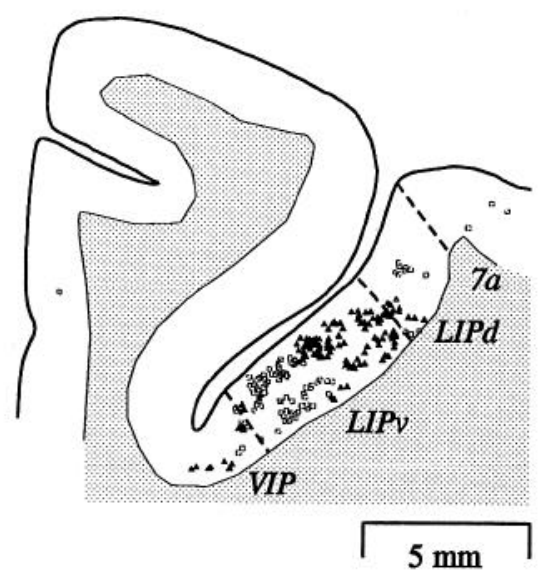

Figure 11. The distributions of retrogradely labeled neurons in the lateral bank of the intraparietal sulcus after injections of different tracers into lateral and more central locations in the FEF in case AM13. The upper diagram shows a dorsolateral view of the cortex illustrating by the arrows the portion of the intraparietal sulcus containing labeled cells, the levels of illustrated coronal sections, and the relative locations of the tracer injections in prearcuate cortex. Distributions of labeled neurons are portrayed below in flattened reconstructions of the lateral bank of the intraparietal sulcus from coronal sections. Caudal is to the left. The solid line at the top of the reconstructions represents the dorsal lip of the sulcus. The dotted line at the bottom represents the fundus. Dashed lines indicate the labeled areal boundaries. The left panel illustrates the relative density of labeled neurons; solid black triangles indicate the position of neurons labeled by the FB injection in medial area 45a, and open gray squares, the position of neurons labeled by the DY injection in lateral area $8 \mathrm{Ac}$. The right panel summarizes the distributions of afferent neurons to central and centrolateral FEF by outlining regions of labeled neurons; right hatching indicates neurons labeled by the lateral prearcuate injection, and left hatching, neurons labeled by the medial prearcuate injection. Overlap between the different populations of retrogradely labeled neurons is illustrated by cross-hatching. Portions of coronal sections are also shown. 
AM55
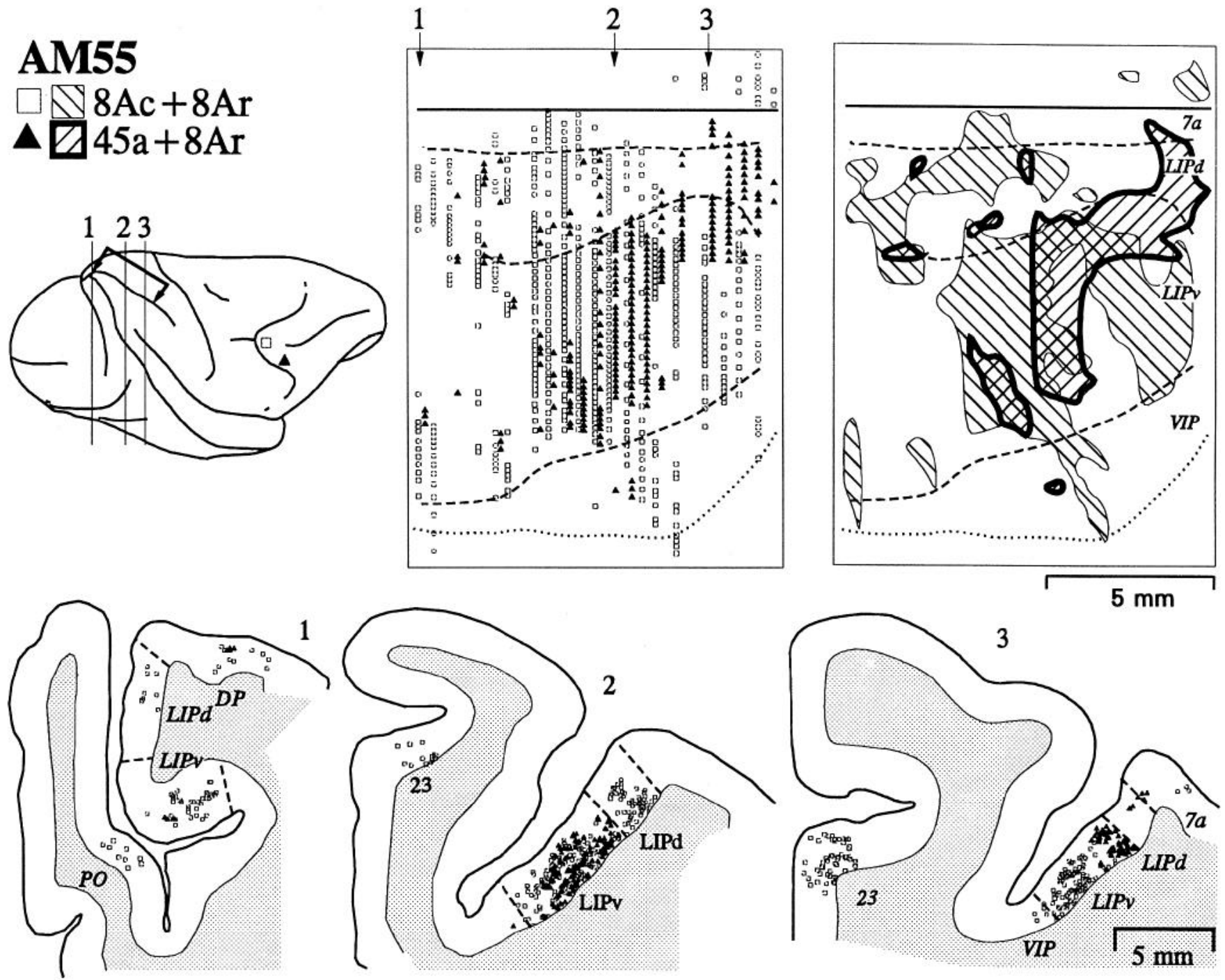

Figure 12. Retrogradely labeled neurons in the lateral intraparietal region in case AM55. Conventions are as in Figure 11.

cortex in a region corresponding to area MDP. Still further rostral neurons labeled from the $8 \mathrm{Ac}$ plus $8 \mathrm{Ar}$ injection were found in upper and lower layers of cingulate cortex area 23 (Fig. 9E).

In case AM55, neurons labeled by the area 8Ac injection but not by the area 45a injection were found in PO (Figs. 10B, 12). In this case the labeled neurons in PO were in both supra- and infragranular layers. In cingulate area 23 , a large number of neurons in upper and lower layers labeled from 8Ac injection but not the area 45 injection were found in this case (Fig. $10 \mathrm{C}$ $E$ ). However, few neurons were found in area MDP in this monkey. In case AM25, many neurons in PO were labeled by the injection in area $8 \mathrm{Ac}$ and $8 \mathrm{Ar}$ but not by the injection in $45 \mathrm{a}$ and 45b (Fig. 13). In this case, the neurons labeled in PO were most commonly in the supragranular layers. Sparse neurons labeled from the dorsomedial arcuate injection were found in MDP in this monkey, and many upper and lower layer neurons were labeled in area 23 of cingulate cortex (not shown).

\section{Superior temporal sulcus}

The spatial distribution of retrogradely labeled neurons in the superior temporal sulcus of case AM13 is shown in Figure 14. Neurons labeled by injections in different parts of prearcuate cortex in this case were observed in all identified areas in the superior temporal sulcus. Neurons labeled by the injection in area 45 were found throughout MT but were concentrated rostrolaterally, whereas neurons labeled by the dorsomedially adjacent injection in $8 \mathrm{Ac}$ in prearcuate cortex were restricted to the caudal portion of MT. Thus, injections into the shorter saccade representation in FEF labeled neurons in the part of MT representing the central visual field, and injections into the longer saccade representation in FEF labeled cells in the peripheral visual field representation of MT (Gattas and Gross, 1981; Van Essen et al., 1981; Desimone and Ungerleider, 1986; Erickson et al., 1989). The cells labeled in MT in this case were most common in the infragranular layers and in deep layer 3 . Neurons labeled by all three injections in prearcuate cortex were found in MST in both supra- and infragranular layers. In the densely myelinated part of MST on the upper bank the cells labeled from injections in 8Ac were most abundant, and these extended beyond the dorsal border of the densely myelinated zone toward the dorsal lip of the sulcus. As shown in the coronal sections, some of this label extended over the superior temporal gyrus and caudal lateral fissure into caudal auditory areas corresponding to area Tpt (Galaburda and Pandya, 1983) or alternatively 

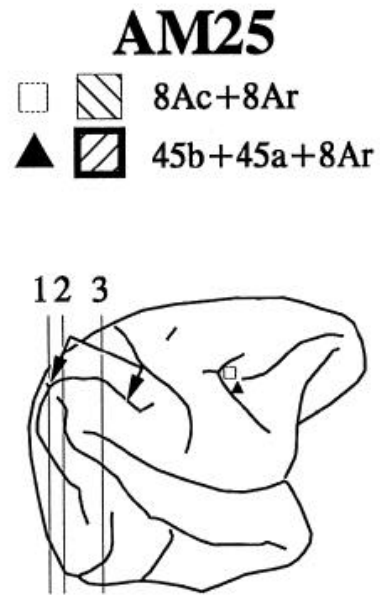
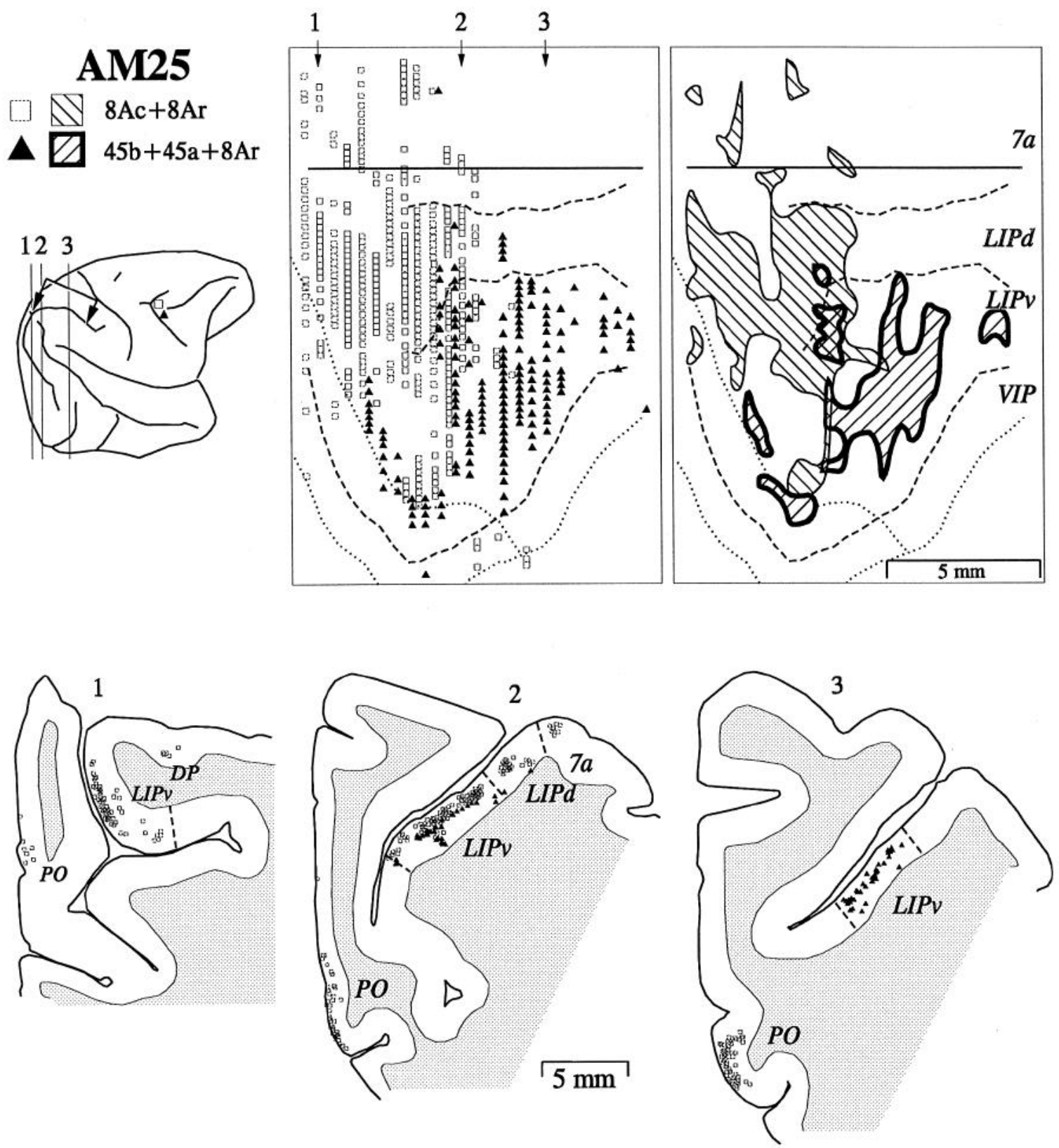

Figure 13. Retrogradely labeled neurons in the lateral intraparietal region in case AM25. Conventions are as in Figure 11.

areas C and part of PL (Morel et al, 1993). Scattered neurons labeled by the 45 a injection were also observed in MST, being somewhat more concentrated in the lateral portion of MST bordering MT and FST. Moving rostral, neurons labeled from the injection involving area 45a were found in area PITd rostral to MT in the lower bank of the sulcus; scattered neurons labeled from the central FEF injection were also seen in this area in upper and lower cortical layers. Neurons labeled by the ventrolateral FEF injection were also dense in FST where they were intermixed with neurons labeled from ventral area $8 \mathrm{Ac}$. Some mixing of neurons labeled by the ventral and central injections was also seen further rostral in PGa. Low concentrations of labeled neurons were observed in TEm, TEa, and IPa. Neurons labeled form 8Ac were more common in the upper bank of the superior temporal sulcus, primarily in area TPO but also in TS and TAa. The labeled neurons in the rostral superior temporal sulcus were concentrated in the deeper layers but were also found in the upper layers.

The distribution of retrogradely labeled neurons in case AM55 is shown in Figure 15. The pattern of label was somewhat different from that observed in the previous case because of the different relative locations of the injections in prearcuate cortex. In this case, one tracer was injected further ventrolaterally in area $45 \mathrm{a}$ as compared to the corresponding injection in case AM13. The dorsomedial injection also was further from the area 45/8a border in AM55 than in AM13. In V4t, neurons were labeled by the ventrolateral but not the medial prearcuate injection. The ventrolateral injection labeled neurons in rostrolateral MT, while the more medial prearcuate injection labeled neurons in caudal and medial MT. The cells labeled in MT from FEF were most common in the lower part of layer 3, although labeled neurons were also found in the infragranular layers. In MST, the 
great majority of cells were labeled by the medial prearcuate injection in $8 \mathrm{Ac}$, and the neurons were dense in both upper and lower cortical layers. As in the previous case, these labeled neurons extended beyond the densely myelinated zone, over the dorsal lip of the sulcus into area Tpt. In MST, at the fundus bordering MT and FST, a mixture of neurons were labeled by both injections. Approximately equal densities of cells labeled from both injections were intermixed in FST. Neurons from 8Ac were dense in the rostral upper bank of the superior temporal sulcus, in areas TS, TAa, TPO, and PGa. Intermixed labeled cells were seen in caudal PGa and IPa. In the lower bank of the superior temporal sulcus neurons were labeled essentially exclusively by the ventrolateral injection, but the cells were restricted to TEa and avoided TEm over the lower lip of the sulcus. The neurons labeled in these rostral areas were most dense in the infragranular layers.

Figure 16 illustrates the spatial distribution of cells labeled by ventrolateral and dorsomedial injections in prearcuate cortex of case AM25. The general pattern of connectivity of ventrolateral prearcuate cortex to the lower bank of the superior temporal sulcus and dorsomedial prearcuate cortex with the upper bank of the superior temporal sulcus was replicated in this case. Cells labeled from area 45 were found in V4t. In comparison to the other two cases, curiously there was much less label in MT and MST in this case. The labeled cells in MT were found most often in deep layer 3, while those in MST were found in supraand infragranular layers. The cells labeled from 45 in MT were found rostrolaterally, and the connected with $8 \mathrm{Ac}$ cells were caudal. In the densely myelinated portion of MST, cells labeled by the ventral injection were scattered, and cells labeled from the dorsomedial injection were concentrated caudally. Unlike in the previous two cases, only a limited cluster of labeled neurons was found in Tpt adjacent to the densely myelinated part of MST. In the part of MST bordering MT and FST a higher density of cells labeled by the ventral tracer was found, as was the case in FSl. Intermixed neurons labeled from both injections were found in caudal PGa, adjacent to FST. More rostral in PGa, TPO, and TAa, only ncurons labcled from $8 \mathrm{Ac}$ werc found, and these were densest in the infragranular layers. In caudal TPO were scattered labeled cells from the ventrolateral FEF injection. In the ventral bank of the superior temporal sulcus, cells labeled form area 45 predominated with limited mixing of labeled cells in $\mathrm{IPa}$.

\section{Inferior temporal gyrus}

The distribution of neurons in the inferior temporal gyrus labeled by paired prearcuate injections in case AM13 is shown in Figure 14. A cluster of cells labeled by the centrally located injection in lateral $8 \mathrm{Ac}$ and $8 \mathrm{Ar}$ was evident on the convexity between the caudal superior temporal sulcus and the lunate sulcus. Scattered clusters of cells labeled by the ventrolateral injection in $45 \mathrm{a}$ and $8 \mathrm{Ar}$ were found extending from the medial bank of the inferior occipital sulcus through the caudal occipitotemporal sulcus as far rostral as the end of the posterior middle temporal sulcus. Cells labeled from the injection in area $8 \mathrm{Ac}$ were also observed in the caudal occipitotemporal sulcus. This region is probably area V4, but may include some of $\mathrm{V} 3 \mathrm{v}$. A cluster of neurons labeled from area $8 \mathrm{Ac}$ and $8 \mathrm{Av}$ was also seen in the posterior middle temporal sulcus, in area TEO. Neurons labeled in these regions were most common in the supragranular layers.

Figure 15 illustrates the distribution of labeled neurons in case AM55. Ventral to the superior temporal sulcus the large majority

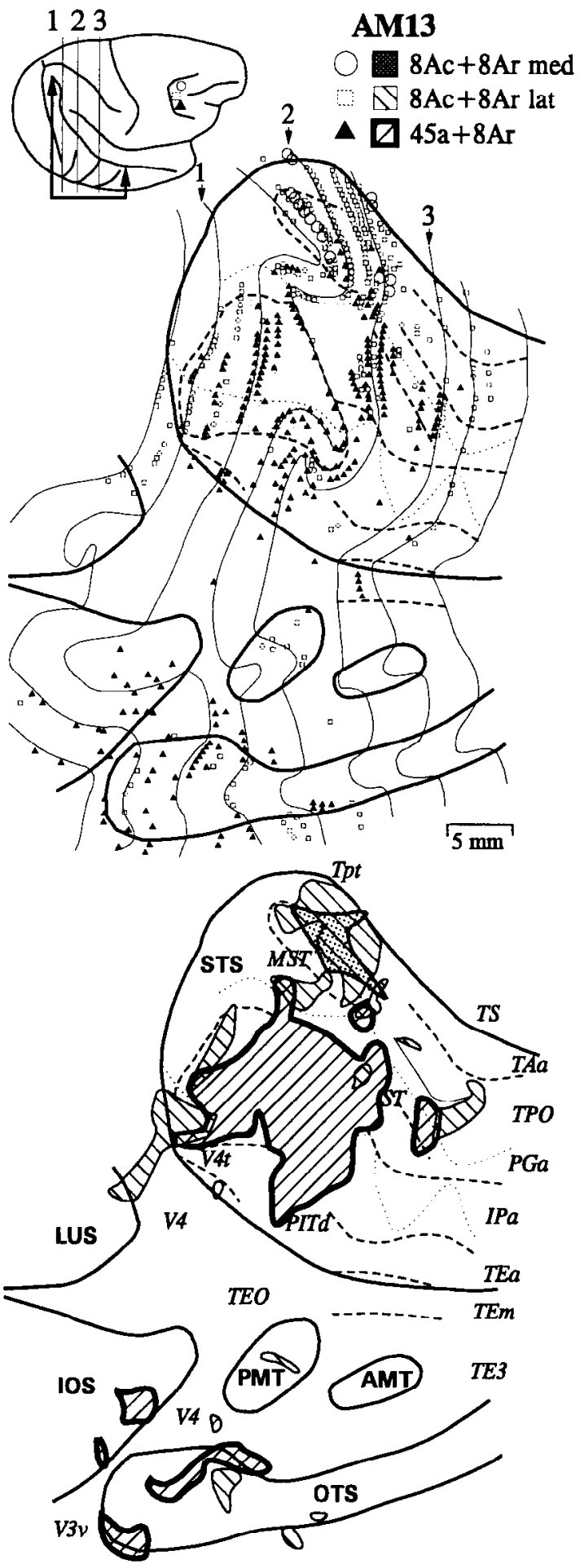

Figure 14. Retrogradely labeled neurons in the superior temporal sulcus and inferior temporal gyrus in case AM13. Conventions are as in Figure 11 except the location of neurons retrogradely labeled by the dorsomedial FG injection are illustrated with open black circles. The shaded areas in the unfolded superior temporal sulcus represent area MT ventrally and the densely myelinated part of MST dorsally. The various sulci are identified as follows: STS, superior temporal sulcus; $L S$, lateral sulcus; $I O S$, inferior occipital sulcus; $P M T$, posterior middle temporal sulcus; $A M T$, anterior middle temporal sulcus; OTS, occipitotemporal sulcus. The rostral limit of the densely myelinated part of MST could not be determined in this case due to damage of the myelin stained tissue. 

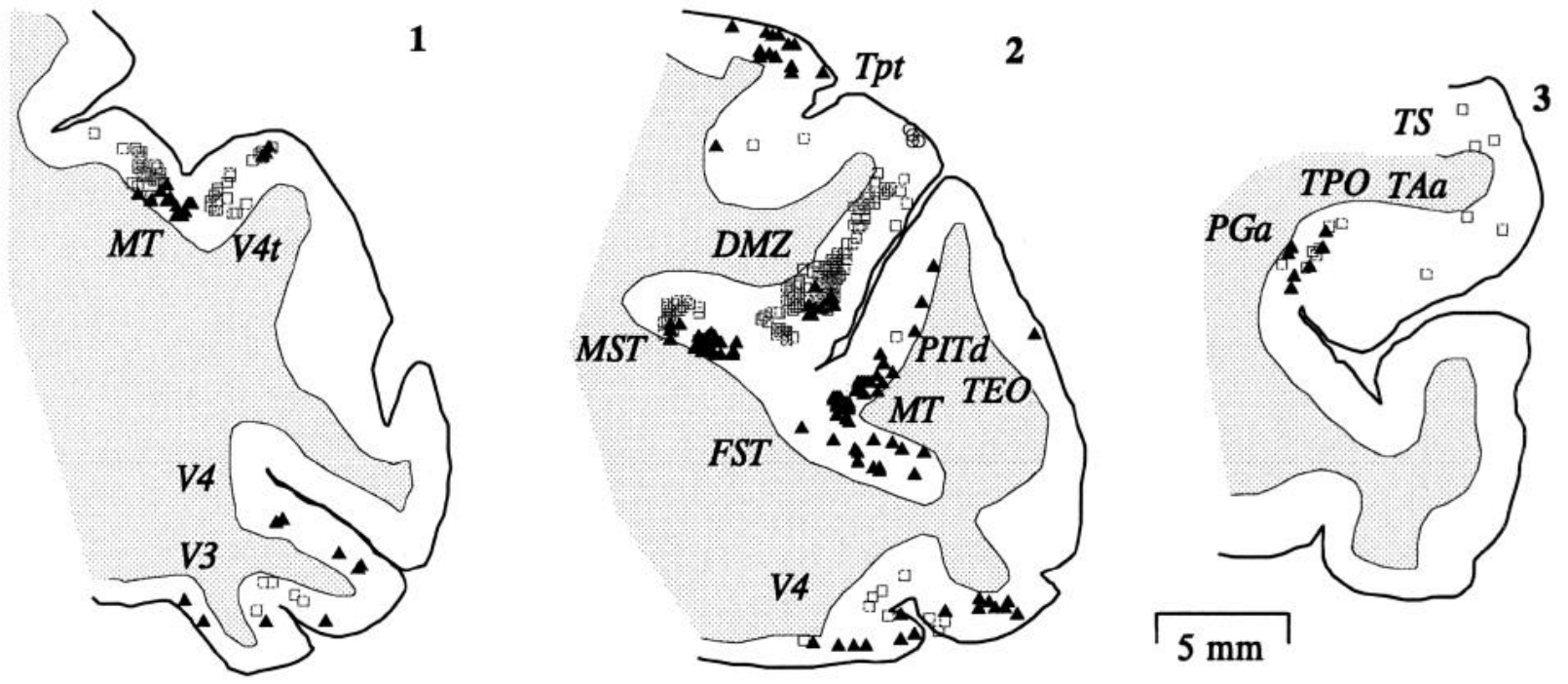

Figure 14. Continued.

of neurons were labeled by the ventrolateral prearcuate injection. Such cells were observed in V4, TEO, and TE3, and with low incidence in $\mathrm{V} 3 \mathrm{v}$. The much higher density of neurons labeled by the ventrolateral prearcuate injection in this case may be attributed to the fact that the injection was located further ventrolaterally in area $45 \mathrm{a}$ as compared to the other two cases. Based on the map of saccade amplitude (Bruce et al., 1985) and of the visual field (Suzuki and Azuma, 1983) in prearcuate cortex, we surmise that the ventrolateral injection in this case was located in a part of FEF representing very short saccades and the perifoveal visual field. This representation is consistent with the finding of a high number of labeled neurons on the inferior temporal gyrus, near the tip of the inferior temporal sulcus where the central visual field is represented, and in area TE3. These neurons were most common in the supragranular layers but were also found in the deeper layers. The few neurons labeled by the centromedial prearcuate injection in $8 \mathrm{Ac}$ were found in the lower bank of the inferior occipital sulcus and in the medial bank of the occipitotemporal sulcus, in the representation of the peripheral visual field. Moving rostral into area TE3, the density of neurons labeled from the area $8 \mathrm{Ac}$ injection was markedly reduced.

The distribution of labeled neurons in the inferior temporal cortex in case AM25 is shown in Figure 16. The distribution of labeled neurons in this case was comparable to that in case AM13 in having no neurons labeled on the surface of the inferior temporal gyrus. Neurons labeled by the injection in dorsomedial area $45 \mathrm{a}$ and $45 \mathrm{~b}$ were located ventral to the inferior occipital sulcus, and were most dense ventral to the posterior middle temporal sulcus, in the lateral bank of the occipitotemporal sulcus. These neurons were most commonly supragranular. As in case AM13, the location of the few neurons labeled by the injection in areas $8 \mathrm{Ac}$ plus $8 \mathrm{Ar}$ relative to the visual field representation corresponded to the relative difference in saccade amplitude represented in FEF. Also as in case AM13, very few neurons were found in TEm or TE3.

\section{Discussion}

Three observations motivated this study. First, the visual system is organized in two processing streams, one involving temporal cortex that is responsible for object vision, and the other in- volving parietal cortex that is responsible for spatial vision (reviewed by Merigan and Maunsell, 1993). Some understanding of how these two streams combine for perception and action can be gained by examining their connectivity with frontal cortex and specifically the visuomotor area FEF. Second, whereas the acuity and specificity for color and form of central vision guides short-amplitude saccades, longer saccades are guided by the more sensitive visual processing subserved by peripheral retina (e.g., Viviani, 1990; Rayner, 1992). Third, the final stage of cortical processing before purposive, visually guided saccades occurs in FEF (Bruce and Goldberg, 1985; Segraves and Goldberg, 1987; Schall, 1991b; Dassonville et al., 1992; Segraves, 1992) in which saccade amplitude is mapped with shorter saccades represented ventrolaterally and longer saccades, dorsomedially (Bruce et al., 1985).

This study is the first direct examination of the topography of visual cortical afferents to FEF using multiple tracer injections in the same monkey, analyzing the distribution of labeled neurons in terms of the most current descriptions of prestriate cortical areas. A number of studies have described the cortical afferents to FEF (reviewed by Leichnetz and Goldberg, 1988), and the general topographic patterns of connectivity that were found have been indicated in earlier studies comparing results across monkeys (e.g., Barbas and Mesulam, 1981; Huerta et al., 1987; Arikuni et al., 1988; Leichnetz, 1989, 1990; Stanton et al., 1993). By making paired tracer injections in each monkey, we described the convergence and segregation of frontal lobe connections with both posterior parietal and inferotemporal cortex. Morel and Bullier $(1987,1990)$ and Baizer et al. (1991) described overlapping label in the rostral bank of the arcuate sulcus following paired injections in inferior temporal and posterior parietal cortex, but the present study provides significantly more information by analyzing the data with refined architectural criteria and by relating the findings to results from multiple injections in FEF. The results are summarized in Figure 17.

Consistent with earlier work, we found that areas $8 \mathrm{Ac}, 45 \mathrm{a}$, $45 \mathrm{~b}$, and also $8 \mathrm{Ar}$ were innervated by V2, V3, and V4 (Barbas, 1988; Tanaka et al., 1990; but see Huerta et al., 1987), MT (Maioli et al., 1983; Ungerleider and Desimone, 1986b; Huerta 

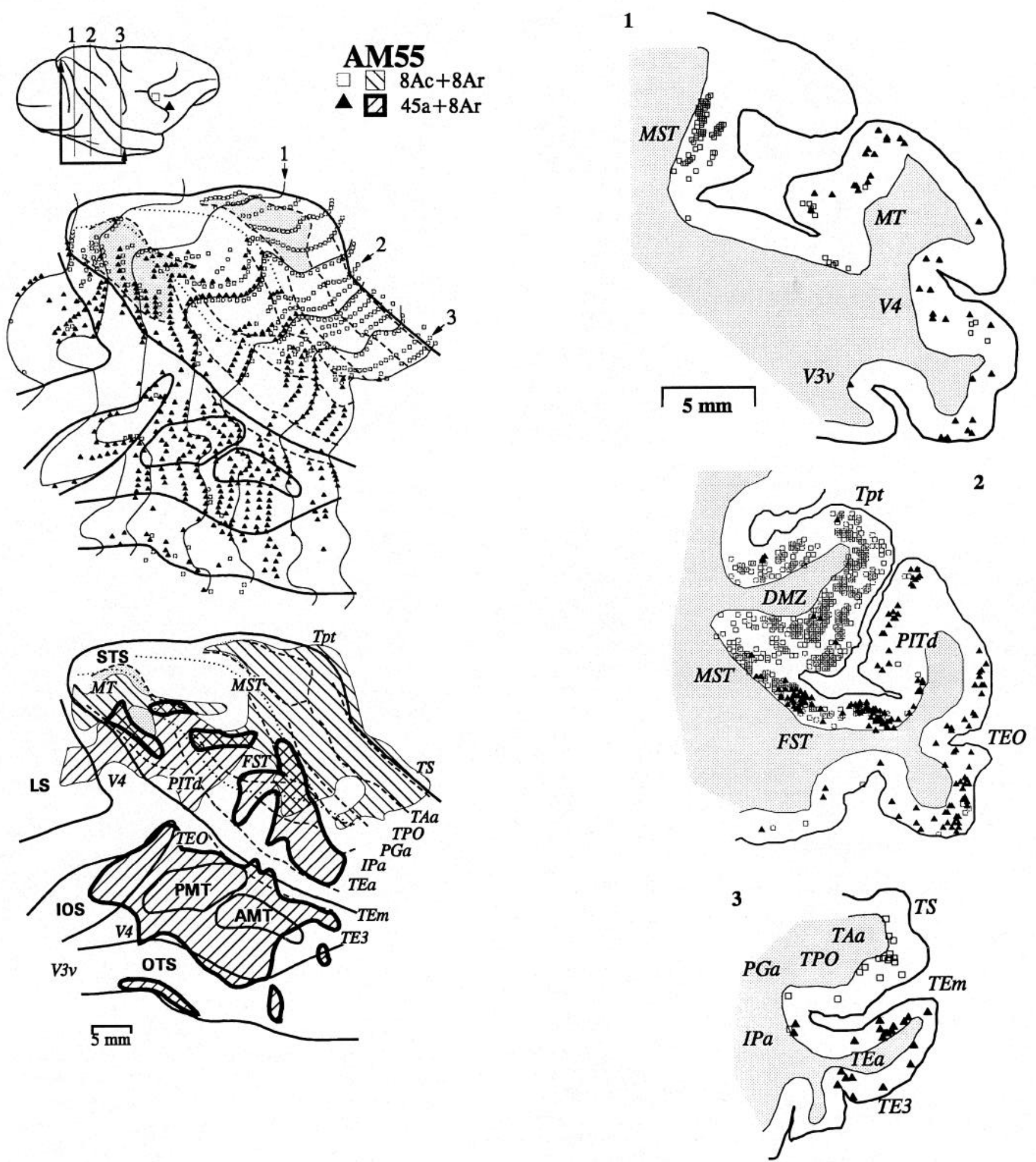

Figure 15. Retrogradely labeled neurons in the superior temporal sulcus in case AM55. Conventions are as in Figure 14.

et al., 1987; Leichnetz and Goldberg, 1988; Leichnetz, 1989, 1990; Krubitzer and Kaas, 1990), and TEO (Morel and Bullier, 1987; Baizer et al., 1991; Distler et al., 1993). Projections from MT and TEO were heavy; those from V4 were moderate, and those from V3 and V2 were very light. We consistently observed that medial FEF was innervated by cells in regions V4, TEO, and MT corresponding to the representation of the peripheral visual field, and that lateral FEF received afferents from the central visual field representation of these areas. These data indicate that visual information specific for local color, form, and motion converges topographically in FEF. The observation that the innervation of FEF and surrounding cortex by areas V2, V3, and V4 was weaker than the innervation by association areas such as TEO, MT, or MST suggests that color, form, and motion 

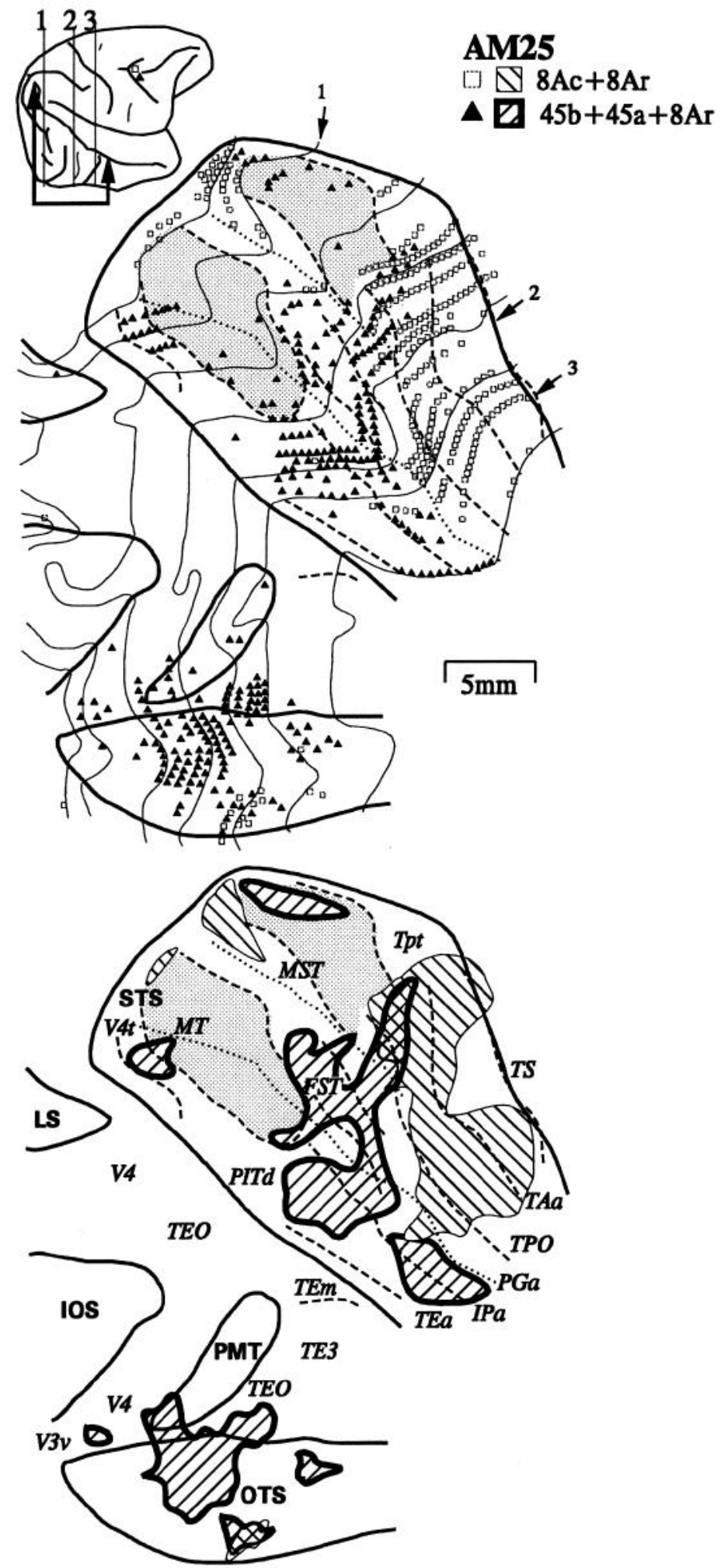

1

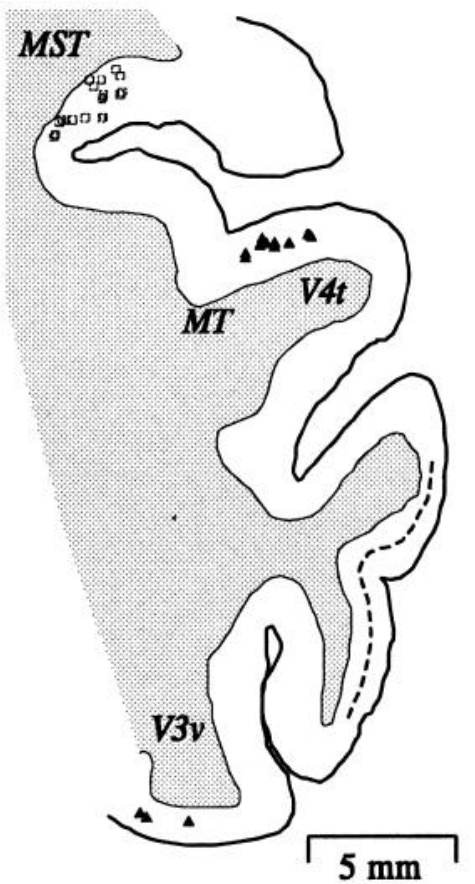

2

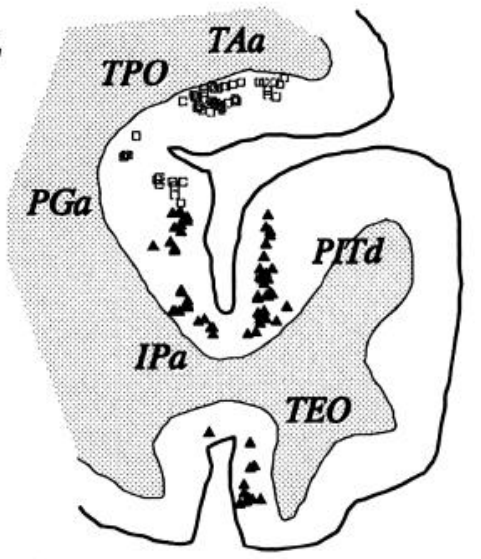

3

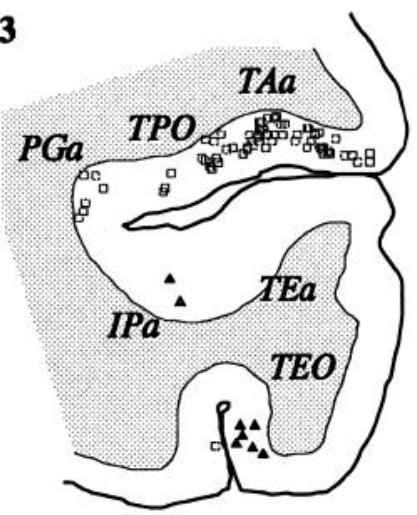

Figure 16. Retrogradely labeled neurons in the superior temporal sulcus in case AM25. Conventions are as in Figure 14.

information undergoes several stages of processing before it is used to guide saccadic eye movements.

We found that LIPv and LIPd projected to most if not all of the rostral bank of the arcuate sulcus, including areas $8 \mathrm{Ac}, 45 \mathrm{a}$, and $45 \mathrm{~b}$ as well as medial and lateral $8 \mathrm{Ar}$, and that LIPv input to FEF was much stronger than that from LIPd. Extending ear- lier observations (Petrides and Pandya, 1984; Andersen et al., 1985, 1990a; Leichnetz and Goldberg, 1988; Cavada and Goldman-Rakic, 1989; Blatt et al., 1990). We also observed a rough tendency for rostral LIPv to project to area 45, and caudal LIPv, to area $8 \mathrm{Ac}$. This general topographic relation between FEF and LIP is consistent with an earlier study by Blatt et al. (1990), 


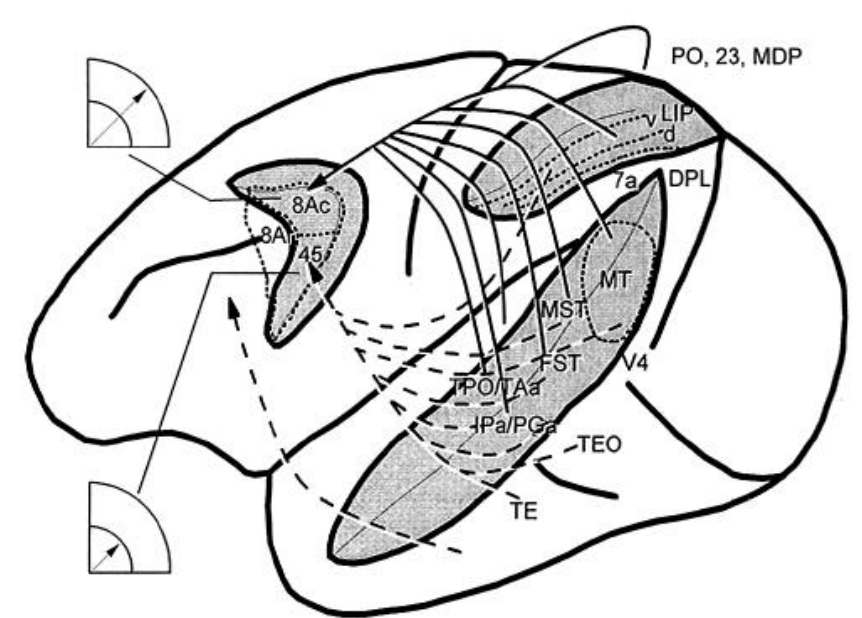

Figure 17. Summary of major connections of FEF with visual cortical areas. The location of specific cortical areas is indicated on a dorsolateral view of the macaque brain. The relative amplitude of saccades represented by ventral FEF (area 45) and dorsal FEF (area 8Ac) is indicated. The solid lines indicate major projections to area $8 \mathrm{Ac}$, and the dashed lines represent major projections to area 45 .

who reported that caudal LIP is connected to medial $8 \mathrm{~A}$ and central-rostral LIP, to lateral area $8 \mathrm{~A}$. This observation suggests the presence of some sort of mapping in LIP related to saccade amplitude. Physiological studies of LIP present variable results. Kurylo and Skavenski (1991) showed that microstimulation of caudal LIP evoked fixed vector saccades, and saccades converging on a particular point were most often evoked by stimulation of rostral regions. In contrast, Thier and Andersen (1991) provided preliminary evidence that stimulation of the lateral bank of the intraparietal sulcus elicited only contraversive saccades with fixed vector trajectories, whereas stimulation of the fundus of the intraparietal sulcus evoked convergent saccades accompanied by movements of the face, ears, and shoulders. The visual field representation in the intraparietal sulcus has the central visual field represented dorsally, and the peripheral visual field, ventrally (Blatt et al., 1990). None of these patterns corresponds very clearly to the observed organization of LIP connections with FEF. Further work is needed to resolve the nature of the mapping between FEF and LIP.

Cortical areas representing the peripheral visual field and polysensory areas projected preferentially to dorsomedial FEF. Areas $8 \mathrm{Ac}$ and medial $8 \mathrm{Ar}$ were innervated by MSTd, PO, TPO, $\mathrm{TAa}$, and area 23 , which were heavily labeled, while neurons projecting from areas V3A, MDP, DP, and 7a were lightly labeled. Many of these projections to FEF have been observed (Leichnetz, 1980; Barbas and Mesulam, 1981; Petrides and Pandya, 1984; Huerta et al., 1987; Barbas, 1988; Colby et al., 1988; Leichnetz and Goldberg, 1988; Leichnetz, 1989; Seltzer and Pandya, 1989; Andersen et al., 1990a; Boussaoud et al., 1990). However, projections from MDP and area 23 to FEF have not been reported before. The role in gaze control of the visual information conveyed by these different areas is not known. Recent evidence indicates that neurons in area 23 respond best to large visual stimuli and postsaccadically in association with long saccades (Musil et al., 1991, 1992).

The preferential projection of MSTd to the long saccade representation of FEF may be involved in the mutual interaction of gaze control and heading during locomotion (e.g., Warren et al., 1988; Royden et al., 1992) because neurons in MSTd respond to large optic flow stimuli (e.g, Duffy and Wurtz, 1991). Areas TAa and TPO in the dorsal bank of the superior temporal sulcus correspond to the superior temporal polysensory area in which neurons respond to large, moving visual stimuli (Bruce et al., 1981; Baylis et al., 1987). Activity related to visually guided saccades has been recorded in the dorsal bank of the superior temporal sulcus (Colby and Miller, 1986).

An auditory area in the caudal superior temporal gyrus projected to dorsomedial but not ventrolateral FEF as observed before (Petrides and Pandya, 1988). Cells in this region were labeled by an injection into a zone in medial prearcuate cortex from which pinna movements were evoked by microstimulation. Neurons in this auditory area respond to localized acoustic stimuli as well as to tactile stimuli around the pinna (Leinonen et al., 1980). Thus, responses of neurons in the upper limb of the arcuate to acoustic stimuli (Azuma and Suzuki, 1984; Vaadia et al., 1986; Schall, 1991b) may originate in this projection. The part of FEF that generates longer saccades, thus receives information from the peripheral visual field as well as acoustic and possibly tactile inputs. Long gaze shifts including both eye and head rotation are commonly made to orient to peripheral visual or acoustic stimuli.

Visual areas TEa, TE3, TEm, and TF in caudal inferotemporal cortex that have overrepresentations of the central visual field projected preferentially to ventrolateral FEF, areas $45 \mathrm{a}, 45 \mathrm{~b}$, and lateral $8 \mathrm{Ar}$. This observation is consistent with earlier studies (e.g., Barbas and Mesulam, 1981; Morel and Bullier, 1987; Weller and Kaas, 1987; Ungerleider et al., 1989; De Lima et al., 1990; Baizer et al., 1991). We found that the temporal lobe connections were largely limited to areas $45 \mathrm{a}$ and $45 \mathrm{~b}$ in FEF, providing new evidence for the functional distinction between medial and lateral FEF. Neurons in caudal inferotemporal cortex are selective mainly for primary stimulus features such as color or orientation; neurons selective for more elaborate objects including faces are found in rostral inferotemporal cortex (Tanaka et al., 1991). This routing of feature but not complex object information directly to FEF is consistent with the common finding that eye movements are directed to features of objects such as vertices or endpoints (Yarbus, 1967; Kaufman and Richards, 1969; Keating and Keating, 1993). We also noted an absence of temporal lobe afferents from the supplementary eye field, a second region in frontal cortex involved in saccade production (Schlag and Schlag-Rey, 1987; Schall, 1991a). The absence of connections of supplementary eye field with cortical areas involved in object vision is consistent with hypotheses that the two eye fields in frontal cortex play different roles in saccade generation (Schall, 1991a).

Areas MSTI, FST, PITd, IPa, PGa, V4t, and VIP that are not exclusively visual or not retinotopically organized projected to FEF. Most of these connections have been described before (Barbas and Mesulam, 1981; Huerta et al., 1987; Leichnetz and Goldberg, 1988; Boussaoud et al., 1990). Our data indicated that the afferents from these areas are weakly if at all topographically mapped in FEF. Also, connections between FEF and V4t or the newly defined PITd (Boussaoud et al., 1991; Distler et al., 1993) have not been described before. It should be noted that areas $\mathrm{IPa}$ and PGa in the fundus of the rostral superior temporal sulcus are distinguished by being one of the few zones connected with both posterior parietal and inferior temporal cortical areas (Morel and Bullier, 1990; Baizer et al., 1991). Neurons in areas IPa and $\mathrm{PGa}$ are activated by acoustic, tactile as well as visual stimuli, but they exhibit little stimulus specificity (Baylis et al., 
1987). The processing of information from the two processing streams in these areas is not understood nor is their relationship to FFF.

This study has demonstrated that FEF receives afferents from many cortical areas having different functional specializations. A question for further research is how the selective responses of the different visual afferents are expressed in FEF visual responses. Early recordings from visual cells in FEF found infrequent stimulus specificity (Mohler et al., 1973). However, work in area V4 has demonstrated that the degree of response specificity can vary according to how monkeys are using the stimuli (Spitzer et al., 1988). Thus, the visual responses of cells in FEF may exhibit stimulus specificity if tested under the appropriate conditions. Indeed, feature-specific responses have been discovered in ventrolateral prefrontal cortex rostral to FEF in monkeys performing tasks requiring visual object discrimination (Wilson et al., 1993; Sakagami and Niki, 1994). This prefrontal region corresponds to the zone in which we observed labeling from temporal lobe injections. On the other hand, it is possible that single neurons in FEF do not reflect the specificity of their individual afferents because of so much convergence onto FEF neurons from cells with different preferences.

FEF may integrate in some way the signals from multiple visual processing streams to select the target for a saccade. Hypotheses about possible selection mechanisms can be informed by models of visual search that posit the existence of a saliency map encoding the location of conspicuous features attracting attention (e.g., Koch and Ullman, 1985; Treisman, 1988; Cave and Wolfe, 1990). Convergence of multiple, feature-specific processing streams forms the input to such a functional map. A common implementation in these models used to detect salient stimuli involves lateral inhibition to enhance activation representing the location that is most different from its surroundings. Recent evidence indicates that FEF may play such a role in saccade target selection (Schall and Hanes, 1993; Thompson et al., 1993; Schall et al., 1995).

\section{References}

Andersen RA, Asanuma C, Cowan WM (1985) Callosal and prefrontal associational projecting cell populations in area $7 \AA$ of the macaque monkey: a study using retrogradely transported fluorescent dyes. $J$ Comp Neurol 232:443-455.

Andersen RA, Asanuma C, Essick G, Siegel RM (1990a) Curticocortical connections of anatomically and physiologically defined subdivisions within the inferior parietal lobule. J Comp Neurol 296:65113.

Andersen RA, Bracewell M, Barash S, Gnadt J, Fogassi L (1990b) Eye position effects on visual, memory and saccade-related activity in areas LIP and 7a of macaque. J Neurosci 10:1176-1196.

Arikuni T, Watanabe K, Kubota K (1988) Connections of area 8 with area 6 in the brain of the macaque monkey. J Comp Neurol 277:2140.

Azuma M, Suzuki H (1984) Properties and distribution of auditory neurons in the dorsolateral prefrontal cortex of the alert monkey. Brain Res 298:343-346.

Bahill AT, Adler D, Stark L (1975) Most naturally occurring human saccades have magnitudes of 15 deg or less. Invest Ophthalmol 14: 468-469.

Baizer JS, Ungerleider LG, Desimone R (1991) Organization of visual inputs to the inferior temporal and posterior parietal cortex in macaques. J Neurosci 11:168-190.

Barbas H (1988) Anatomic organization of basoventral and mediodorsal visual recipient prefrontal regions in the rhesus monkey. J Comp Neurol 276:313-342.

Barbas H, Mesulam M-M (1981) Organization of afferent input to subdivisions of area 8 in the rhesus monkey. J Comp Neurol 200: $407-431$.
Baylis GC, Rolls ET, Leonard CM (1987) Functional subdivisions of the temporal lobe neocortex. J Neurosci 7:330-342.

Blatt GJ, Andersen RA, Stoner GR (1990) Visual receptive field organization and cortico-cortical connections of the lateral intraparietal area (area LIP) in the macaque. J Comp Neurol 299:421-445.

Boussaoud D, Ungerleider LG, Desimone R (1990) Pathways for motion analysis: cortical connections of the medial superior temporal and fundus of the superior temporal visual areas in the macaque. $J$ Comp Neurol 296:462-495.

Boussaoud D, Desimone R, Ungerleider LG (1991) Visual topography of area TEO in the macaque. J Comp Neurol 306:554-575.

Bruce CJ, Goldberg ME (1985) Primate frontal eye fields. I. Single neurons discharging before saccades. J Neurophysiol 53:603-635.

Bruce CJ, Russo GS (1987) Effects of ketamine on oculomotor function in the monkey. Soc Neurosci Abstr 13:171.

Bruce CJ, Desimone R, Gross CG (1981) Visual properties of neurons in a polysensory area in superior temporal sulcus of the macaque. $\mathbf{J}$ Neurophysiol 46:369-384.

Bruce CJ, Goldberg ME, Bushnell C, Stanton GB (1985) Primate frontal eye fields. II. Physiological and anatomical correlates of electrically evoked eye movements. J Neurophysiol 54:714-734.

Burkhalter A, Felleman DJ, Newsome WT, Van Essen DC (1986) Anatomical and physiological asymmetries related to visual areas V3 and VP in macaque extrastriate cortex. Vision Res 26:63-80.

Cavada C, Goldman-Rakic PS (1989) Posterior parietal cortex in rhesus monkey: II. Evidence for segregated corticocortical networks linking sensory and limbic areas with the frontal lobe. J Comp Neurol 287:422-445.

Cave KR, Wolfe JM (1990) Modeling the role of parallel processing in visual search. Cognit Psychol 22:225-271.

Chelazzi L, Miller EK, Duncan J, Desimone, R (1993) A neural basis for visual search in inferior temporal cortex. Nature 363:345-347.

Colby CL, Duhamel J-R (1991) Heterogeneity of extrastriate visual areas and multiple parietal areas in the macaque monkey. Neuropsychologia 29:517-537.

Colby CL, Miller EK (1986) Eye movement related responses of neurons in superior temporal polysensory area of macaque. Soc Neurosci Abstr 12:1184.

Colby CL, Gattass R, Olson CR, Gross, CG (1988) Topographical organization of cortical afferents to extrastriate visual area $P O$ in the macaque: a dual tracer study. J Comp Neurol 269:392-41.3.

Colby CL, Duhamel J-R, Goldberg ME (1993) Ventral intraparietal area of the macayue: anatomic location and visual response properties. J Neurophysiol 69:902-914.

Dassonville P, Schlag J, Schlag-Rey M (1992) The frontal eye field provides the goal of saccadic eye movements. Exp Brain Res 89: 300-310.

De Lima AD, Voigt T, Morrison JH (1990) Morphology of the cells within the inferior temporal gyrus that project to the prefrontal cortex in the macaque monkey. J Comp Neurol 296:159-172.

Desimone R, Ungerleider L.G (1986) Multiple visual areas in the caudal superior temporal sulcus of the macaque. J Comp Neurol 248: 164-189

Distler C, Boussaoud D, Desimone R, Ungerleider LG (199.3) Cortical connections of inferior temporal area TEO in macaque monkeys. J Comp Neurol 334:125-150.

Duffy CJ, Wurtz RH (1991) Sensitivity of MST neurons to optic flow stimuli. I. A continuum of response selectivity to large-field stimuli. J Neurophysiol 65:1329-1345.

Erickson RG, Dow BM, Snyder AZ (1989) Representation of the fovea in the superior temporal sulcus of the macaque monkey. Exp Brain Res 78:90-112.

Felleman DJ, Van Essen DC (1991) Distributed hierarchical processing in the primate cerebral cortex. Cereb Cortex 1:1-47.

Fries W (1984) Cortical projections to the superior colliculus in the macaque monkey: a retrograde study using horseradish peroxidase. J Comp Neurol 230:55-76.

Galaburda AM, Pandya DN (1983) The intrinsic architectonic and connectional organization of the superior temporal region of the rhesus monkey. J Comp Neurol 221:169-184.

Gallyas F (1979) Silver staining of myelin by means of physical development. Neurol Res 1:203-209.

Gattass R, Gross CG (1981) Visual topography of striate projection zone (MT) in posterior superior temporal sulcus of the macaque. $J$ Neurophysiol 46:621-638. 
Gattas R, Sousa APR, Gross CG (1988) Visuotopic organization and extent of V3 and V4 of the macaque. J Neurosci 8:1831-1845.

Gibson AR, Hansma DI, Houk JC, Robinson FR (1984) A sensitive low artifact TMB procedure for the demonstration of WGA-HRP in the CNS. Brain Res 298:235-241

Godaux E, Cheron G, Mettens P (1990) Ketamine induces failure of the oculomotor neural integrator in the cat. Neurosci Lett 116:162167.

Huerta MF, Krubitzer LA, Kaas JH (1987) Frontal eye fields as defined by intracortical microstimulation in squirrel monkeys, owl monkeys and macaque monkeys. II. Cortical connections. J Comp Neurol 271: 473-492.

Kaufman L, Richards W (1969) Spontaneous fixation tendencies for visual forms. Percept Psychophys 5:85-88.

Keating CF, Keating EG (1993) Monkeys and mug shots: cues used by rhesus monkeys (Macaca mulatta) to recognize a human face. $\mathrm{J}$ Comp Psychol 107:131-139

Koch C, Ullman S (1985) Shifts in selective visual attention: lowards the underlying neural circuitry. Hum Neurobiol 4:219-227.

Komatsu H, Wurtz RH (1988) Relation of cortical areas MT and MST to pursuit eye movements. 1. Localization and visual properties of neurons. J Neurophysiol 60:580 603

Krubitzer LA, Kaas JH (1990) Cortical connections of MT in four species of primates: areal, modular and retinotopic patterns. Vis Neurosci 5: 165-204.

Kurylo DD, Skavenski AA (1991) Eye movements elicited by electrical stimulation of area PG in the monkey. J Neurophysiol 65:12431253.

Leichnetz GR (1989) Inferior frontal cyc ficld projections to the pursuit- related dorsolateral pontine nucleus and middle temporal area (MT) in the monkey. Vis Neurosci 3:171-180.

Leichnetz GR (1990) Preoccipital cortex receives a differential input from the frontal eye field and projects to the pretectal olivary nucleus and other visuomotor-related structures in the rhesus monkey. Vis Neurosei 5:123-133.

Leichnetz. GR, Goldberg ME (1988) Higher centers concerned with eye movement and visual attention: cerebral cortex and thalamus. In Neuroanatomy of the oculomotor system (Büttner-Evvever JA, ed), pp 365-429. New York: Elsevier.

Leinonen L, Hyvärinen J, Sovijärvi ARA (1980) Functional properties of neurons in the tempero-parietal association cortex of awake monkey. Exp Brain Res 39:203-215.

Maguire WM, Baizer JS (1984) Visuotopic organization of the prelunate gyrus in rhesus monkey. J Neurosci 4:1690-1704.

Maioli MG, Squatrito S, Galletti C, Battaglini PP, Sanserverino ER (1983) Corticocortical connections from the visual region of the superior temporal sulcus to frontal eye field in the macaque. Brain Res 265:294-299.

Matelli M, Luppino G, Rizzolatti G (1991) Architecture of superior and mesial area 6 and the adjacent cingulate cortex in the macaque monkey. J Comp Neurol 311:445-462.

Maunsell JHR, Van Essen DC (1983) The connections of the middle temporal visual area (MT) and their relationship to a cortical hierarchy in the macaque monkey. J Neurosci 3:2563-2586.

Merigan WH, Maunsell JHR (1993) How parallel are the primate visual pathways? Annu Rev Neurosci 16:369-402.

Mohler CW, Goldberg ME, Wurtz RH (1973) Visual receptive fields of frontal eye field neurons. Brain Res 61:385-389.

Morel A, Bullier J (1987) Cortical connections of intraparietal and inferotemporal visual areas in the macaque monkey: a double-labeling study. Soc Neurosci Abstr 177:14.

Morel A, Bullier J (1990) Anatomical segregation of two cortical visual pathways in the macaque monkey. Vis Neurosci 4:555-578.

Morel A, Garraghty PE, Kaas JH (1993) Tonotopic organization, architectonic fields and connections of auditory cortcx in macaque monkeys. J Comp Neurol 335:437-459.

Musil SY, Olson CR, Goldberg ME (1991) Posterior cingulate cortex of rhesus monkey: mechanisms of orbital-position and postsaccadic sensitivity. Soc Neurosci Abstr 17:442.

Musil SY, Olson CR, Goldberg ME (1992) Visual response properties of single neurons in posterior cingulate cortex of rhesus monkey. Soc Neurosci Abstr 18:148.

Newsome WT, Maunsell JHR, Van Essen DC (1986) The ventral posterior visual area of the macaque: visual topography and areal boundaries. J Comp Neurol 252:139-153.
Parthasarathy HB, Schall JD, Graybiel AM (1992) Distributed but convergent ordering of corticostriatal projections: analysis of the frontal eye field and the supplementary eye field in the macaque monkey. $\mathrm{J}$ Neurosci 12:4468-4488.

Perkel DH, Bullier J, Kennedy H (1986) Topography of the afferent connectivity of area 17 of the macaque monkey: a double-labeling study. J Comp Neurol 253:374 402.

Petrides M, Pandya DN (1984) Projections to the frontal cortex from the posterior parietal region in the rhesus monkey. J Comp Neurol 228:105-116

Petrides M, Pandya DN (1988) Association fiber pathways to the frontal cortex from the superior temporal region in the rhesus monkey. $J$ Comp Neurol 273:52-66.

Preuss TM, Goldman-Rakic PS (1991) Myelo- and cytoarchitecture of the granular frontal cortex and surrounding regions of the strepsirhine primate Galago and the anthropoid primate Macaca. J Comp Neurol 310:429-474.

Rayner K (1992) Eye movements and visual cognition: scene perception and reading. New York: Springer.

Robinson DA, Fuchs AF (1969) Eye movements evoked by stimulation of frontal eye fields. J Neurophysiol 32:637-648.

Royden CS, Banks MS, Crowell JA (1992) The perception of heading during eye movements. Nature 360:583-585.

Sakagami M, Niki H (1994) Encoding of behavioral significance of visual stimuli by primate prefrontal neurons: relation to relevant task conditions. Exp Brain Res 97:423-436.

Schall JD (1991a) Neuronal activity related to visually guided saccadic eye movements in the supplementary motor area of rhesus monkeys J Neurophysiol 66:530-558.

Schall JD (1991b) Neuronal activity related to visually guided saccades in the frontal eye fields of rhesus monkeys: comparison with supplementary eye fields. J Neurophysiol 66:559-579.

Schall JD, Hanes DP (1993) Neural basis of saccade target selection in frontal eye field during visual search. Nature 366:467-469.

Schall JD, Morel A, King DJ, Whalley C (1991) Topography of connections between cortical visuomotor areas in the macaque. Soc Neurosci Abstr 17.857.

Schall JD, King DJ, Morel A (1993a) Topography of afferents to frontal eye field from superior temporal sulcus in macaque. Soc Neurosc Abstr 19

Schall JD, Morel A, Kaas JH (1993b) Topography of supplementary eye field afferents to frontal eye field in macaque: implications for mapping between saccade coordinate systems. Vis Neurosci 10:385393.

Schall JD, Hanes DP, Thompson KG (1995) Neural correlates of saccade target selection in macaque frontal eye field during visual search. J Neurosci (submitted).

Segraves MA (1992) Activity of monkey frontal eye field neurons projecting to oculomotor regions of the pons. J Neurophysiol 68:19671985

Segraves MA, Goldberg ME (1987) Functional propertics of corticotectal neurons in the monkey's frontal eye fields. J Neurophysiol 58 : 1387-1419.

Seltzer B, Pandya DN (1978) Afferent cortical connections and architectonics of the superior temporal sulcus and surrounding cortex in the rhesus monkey. Brain Res 149:1-24

Seltzer B, Pandya DN (1989) Frontal lobe connections of the superior temporal sulcus in the rhesus monkey. J Comp Neurol 281:97-113.

Spitzer H, Desimone R, Moran J (1988) Increased attention enhances both behavioral and neuronal performance. Science 240:338-340.

Stanton GB, Goldberg ME, Bruce CJ (1988) Frontal eye field efferents in the macaque monkey: I. subcortical pathways and topography of striatal and thalamic terminal fields. J Comp Neurol 271:473-492.

Stanton GB, Deng S-Y, Goldberg ME, McMullen NT (1989) Cytoarchitectural characteristics of the frontal eye fields in macaque monkeys. J Comp Neurol 282:415-427.

Stanton GB, Bruce CJ, Goldberg ME (1993) Topography of projections to the frontal lobe from the macaque frontal eye fields. J Comp Neurol 330:286-301.

Suzuki H, Azuma M (1983) Topographic studies on visual neurons in the dorsolateral prefrontal cortex of the monkey. Exp Brain Res 53: $47-58$.

Tanaka K, Saito H-A, Fukada Y, Moriya M (1991) Coding visual images of objects in the inferotemporal cortex of the macaque monkey. J Neurophysiol 66:170-189. 
Tanaka M, Lindsley E, Lausmann S, Creutzfeldt OD (1990) Afferent connections of the prelunate visual association cortex (areas V4 and DP). Anat Embryol 181:19-30.

Thier P, Andersen, RA (1991) Electrical microstimulation delineates 3 distinct eye-movement related areas in the posterior parietal cortex of the rhesus monkey. Soc Neurosci Abstr 17:1281.

Thompson KG, Hanes DP, Tu FF, Schall JD (1993) Evolution of saccade target selection signal in frontal eye field during visual search. Soc Neurosci Abstr 19:27.

Ungerleider LG, Desimone R (1986a) Projections to the superior temporal sulcus from the central and peripheral field representations of V1 and V2. J Comp Neurol 248:147-163.

Ungerleider LG, Desimone R (1986b) Cortical connections of visual area MT in the macaque. J Comp Neurol 248:190-222.

Ungerleider LG, Mishkin M (1982) Two cortical visual systems. In: Analysis of visual behavior (Ingle DJ, Goodale MA, Mansfield RJW, eds), pp 549-586. Cambridge, MA: MIT Press.

Ungerleider LG, Gaffan D, Pelak VS (1989) Projections from inferior temporal cortex to prefrontal cortex via the uncinate fascicle in rhesus monkeys. Exp Brain Res 76:473-484.

Vaadia E, Benson DA, Hienz RD, Goldstein MH (1986) Unit study of monkey frontal cortex: active localization of auditory and of visual stimuli. J Neurophysiol 56:934-952.

Van Essen DC, Maunsell JHR (1980) Two-dimensional maps of the cerebral cortex. J Comp Neurol 191:255-281.

Van Essen DC, Zeki SM (1978) The topographic organization of rhesus monkey prestriate cortex. J Physiol (Lond) 277:193-226.
Van Essen DC, Maunsell JHR, Bixby JL (1981) The middle temporal visual area in the macaque: myeloarchitecture, connections, functional properties and topography organization. J Comp Neurol 199:293326.

Van Essen DC, Newsome WT, Maunsell JHR, Bixby JL (1986) The projections from striate cortex (V1) to areas V2 and V3 in the macaque monkey: asymmetries, areal boundaries and patchy connections. J Comp Neurol 224:451-480.

Viviani $P$ (1990) Eye movements in visual search: cognitive, perceptual and motor control aspects. In: Eye movements and their role in visual and cognitive processes (Kowler E, ed), pp 353-393. New York: Elsevier.

von Bonin G, Bailey P (1947) The neocortex of Macaca mulatta. Urbana: University of Illinois.

Walker AE (1940) $\Lambda$ cytoarchitectural study of the prefrontal area of the macaque monkey. J Comp Neurol 73:59-86.

Warren WH, Morris MW, Kalish M (1988) Perception of translational heading from optical flow. J Exp Psychol Hum Percept Perlonn 14: 646-660.

Weller RE, Kaas JH (1987) Subdivisions and connections of inferior temporal cortex in owl monkeys. J Comp Neurol 256:137-172.

Wilson FAW, Ó Scalaidhe SP, Goldman-Rakic PS (1993) Dissociation of object and spatial processing domains in primate prefrontal cortex. Science 260:1955-1958.

Yarbus AL (1967) Eye movements and vision. New York: Plenum.

Young MP (1992) Ohjective analysis of the topological organization of the primate cortical visual system. Nature 358:152-154. 